\title{
1 Ultrafiltration membranes for wastewater and water process engi- neering: a comprehensive statistical review over the past decade
}

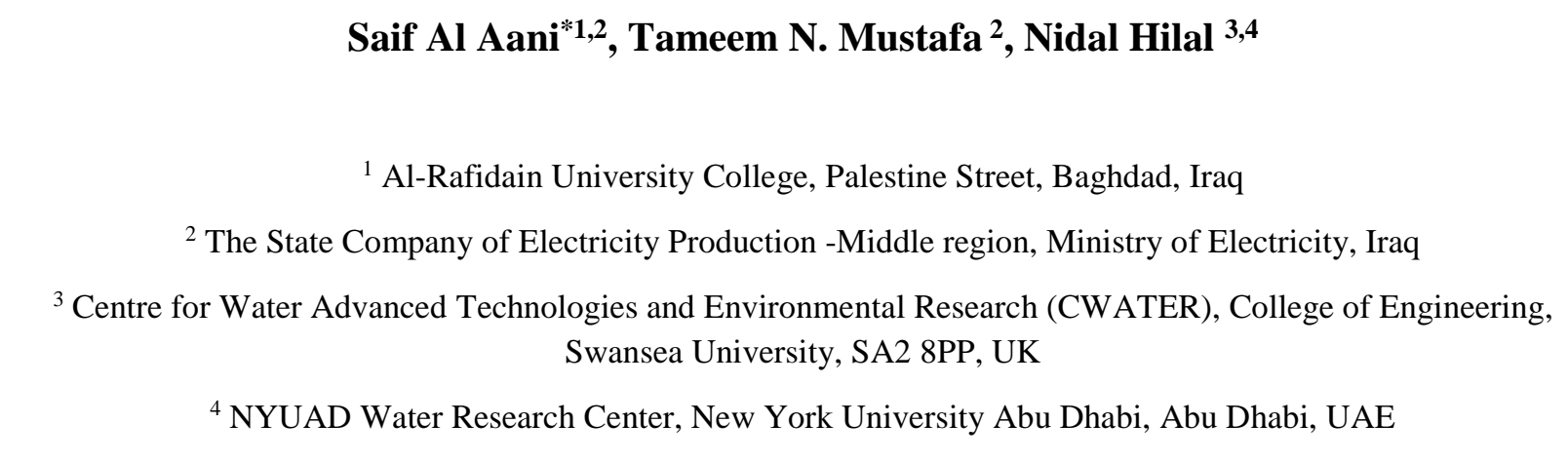

\begin{abstract}
The primary intention of this review is to showcase and quantify the level of research interest and current research trends, concerning UF membrane applications and processes within the past decade (2009-2018). Detected statistics manifested a resurgent interest in the UF technology on a yearly basis. "Journal of Membrane Science" and "Desalination and Water Treatment" were the primary journals dominating the size of the annual publication among more than 120 ones, with 854 and 683 papers, respectively. Based on ScienceDirect research platform, fouling (27\%), modelling (17\%) and wastewater (12\%), were the dominating research topics and counting for more than half of total scientific articles published (4547 articles) within the specified period of the research. Unsurprisingly, topics like UF membrane fabrication and modification, food processing, hybrid membrane process have disclosed a distinguished growing up trends in terms of annual publications. The current review unrevealed the present-day significance of the UF membranes along with their prospective opportunities for attaining sustainable water industries and material-
\end{abstract}


Highlights:

- Fouling, modelling and wastewater are dominating research areas of UF membrane which counted for $27 \%$, $17 \%$, and $12 \%$ of the total publication's size, respectively.

- Journal of Membrane Science was the primary journal dominating the size of the annual publication about UF.

- Fouling of the UF membrane is the largest single area of research interest.

- Potential research trends in UF membrane applications are critically reviewed

*Corresponding author: S. Al Aani (E-mail: saif06_chemeng@yahoo.com)

\section{Outlines}

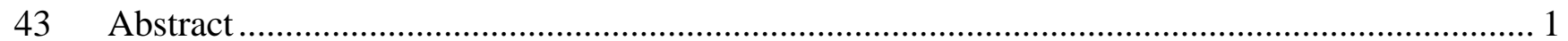

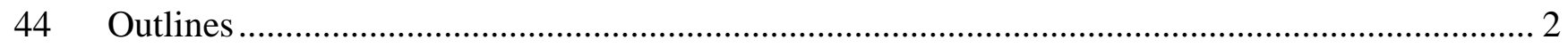

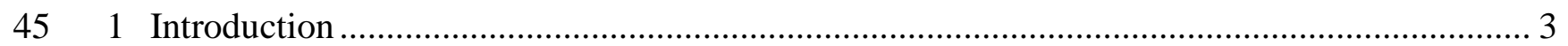

462 Publications on Ultrafiltration over the past decade ..................................................... 4

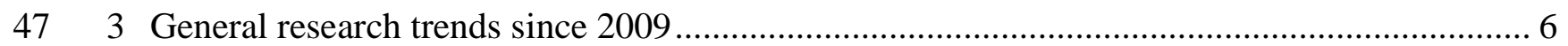

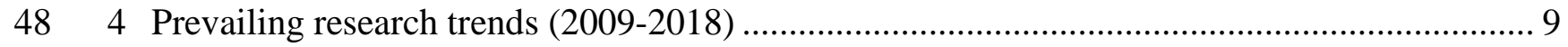

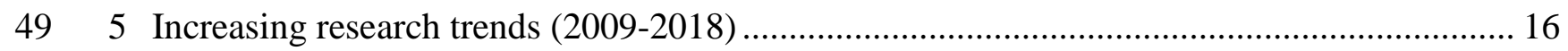

506 Potential trends in UF membrane filtration.................................................................. 22

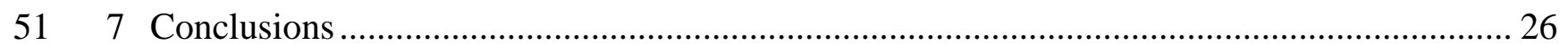

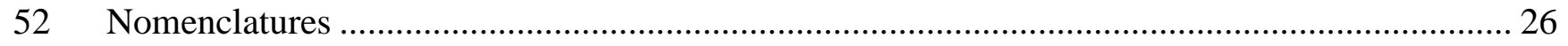

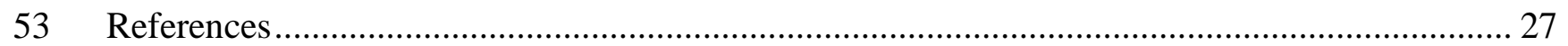




\section{Introduction}

56 The sustainable exploitation of water resources is the backbone for the sustainable evolution of modern society and economy. Along with the rapid development of economy and society, more pressure on the water resources deficiency due to industrialization and human activities has been generated. Diversified techniques have been emerged to clean and renovate polluted waters for industrial, agricultural and human being consumptions. Since their first industrial outset in 1970 for electrophoretic painting, Ultrafiltration (UF) membrane has come a long way as a safe, clean, economical and potent separation tool for a wide range of constituents and contaminants in water and wastewater.

Serving as an outstanding separation technique for more than one century, Ultrafiltration (UF) has been harnessed in membrane filtration to mechanically separate materials from a mixture. The term "Ultrafiltration" was first introduced by Benchold in 1907, forcing solutions at several atmospheres through a membrane [1]. More precisely, the hydrostatic pressure forces induce movement of a liquid to pass through a semipermeable membrane. This separation process targets molecules that contain a higher molecular weight and suspended solids depending on the molecular weight cut-off (MWCO) specified by the specific membrane along with other factors that can take a substantial role, such as molecule shape, charge and hydrodynamic conditions [2]. The main mechanism used for UF is size exclusion, however, depending on the compounds present; reactions between the particles and the membrane might prevent the maximum efficiency of the process.

Market dynamics have led to a surging interest in UF applications, as has been witnessed during the past few decades. Looking for an efficient selective separation technology with low capital cost and longer membrane unit lifespan are some of these dynamics. Steadily, this UF market size trend has risen with the growing environmental awareness concerning water/wastewater treatment technologies, decreasing freshwater resources along with the sustainability policies and stringent regulatory. The UF market was estimated at USD 950.0 million in 2017 and is projected to hit USD 2,140.1 million by 2023. The Dow Chemicals, Koch Membrane System, PennWell Corporation, GE Corporation, Oasys Water is the top 5 global UF membrane companies in the industry. The Koch and Dow Chemical Membrane System dominating the global market with over 51\%unit volume share. Approximately $65 \%$ share of the global membrane market was dominated by the U.S. and Asia Pacific region together mainly due to the rising demand in pharmaceutical, chemical processing, wastewater management etc [3].

UF is an advanced separation technology employed across various industry verticals. It was initially established as a fractionation technique in the late 1960s. Since then, UF membranes have been continuously improved, and its applications have crossed a wide variety of fields, from chemical recovery, cell harvesting, dairy production, medical use, wastewater reclamation, water treatment and juice concentration [4-8]. Particularly, it is well known as a clarification and disinfection

91 separation process has a wide range of applications [9]. The focused applications for this mem- 


\section{3}

114

115

116

117

118

119

120

121

122

123

124

125

126

127

128

129

brane technique lie on the purification and concentration of macromolecules, such as protein solutions in the food industry [10-12]. Other common applications that require the use of ultrafiltration techniques lie in the wastewater sector, fouling, bacteria and virus removal, paint treatment for the metal industry and the textile industry [13-17]. The reasons why UF replaces conventional purification and disinfection process are based on the simplicity and overall cheap process due to low energy usage, fewer control methods, no or less emphasis on chemicals of the process, mild operating temperature and high-quality treatment. At last, introducing technology enables many industries to become eco-friendlier by facilitating the recycling of waste materials and resources recovery $[18,19]$.

With so many journals, papers, articles and documents being presented every day on specific engineering or science topics, it is a very decisive matter for researchers to have a general understanding of what has already been published so that their work does not overlap, or they find themselves doing unnecessary experiments that have already been carried out. That is where literature reviews play a role; they are scholarly papers that involve current knowledge including substantive findings, as well as theoretical and methodological contributions to a particular topic [20]. They are not to report new or original findings but are secondary sources, usually preceding any sections of work. Therefore, this statistical review, about UF technology, has been undertaken for highlighting and tracking various research trends concerning what has been accomplished in water, wastewater and many other applications over the past decade. Along with anticipating research trends and where should be our research prospects in the coming decade.

\section{Publications on Ultrafiltration over the past decade}

With the rapid developments in polymer chemistry, doping, fabrication techniques, modelling as well as applications of membranes as an alternative technology, UF has affirmed their position as an eminent area of research. Virtually, the exact number of articles published was tricky to determine, especially with differing results obtained depending on the database interrogated. In the past few recent years, several statistical review articles have emerged in literature for unlike topics and disciplines [21,22]. Tober (2011) has compared four popular search engines PubMed/MEDLINE, Scopus, ScienceDirect and Google Scholar to assess which search engine is most functional for literature research in laser medicine according to the criteria, recall, precision, and importance. Results disclosed that the most efficacious search engine for an overview of a topic is Scopus, followed by ScienceDirect. A more detailed study can be found elsewhere [23].

Herein, the ScienceDirect database was harnessed as a scientific platform for detecting the research statistics across the spectrum of available journals. The search was specified to only involve academic articles and reviews that virtually related to term "Ultrafiltration". The later processing of data has eliminated any article or review that encloses text e.g. 'ultrafiltration' but does not virtually fit to the respective field. For instance; the term ultrafiltration may appear rightfully in the manuscript while specifically, the main theme was identified dealing with nanofiltration. At 


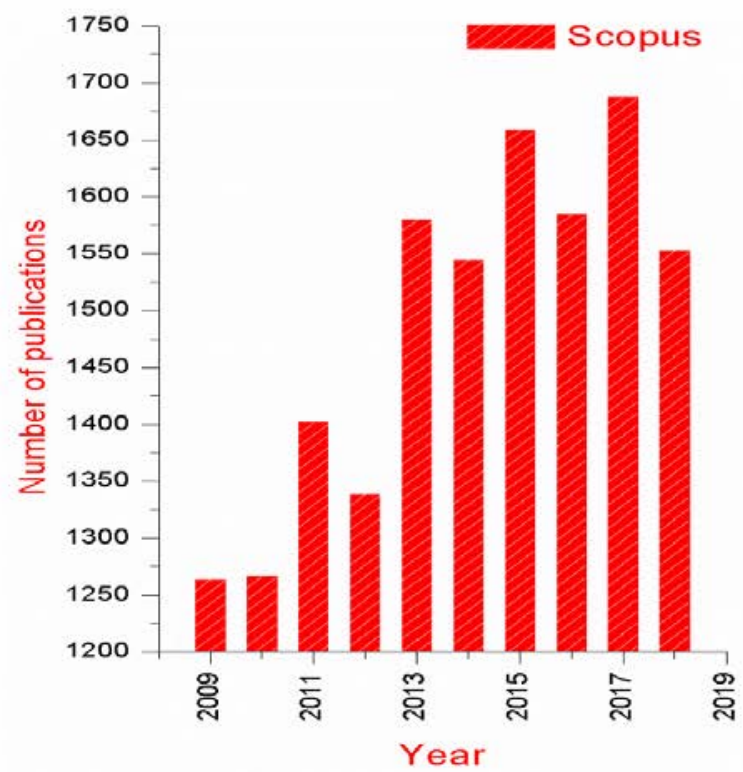
in 2017 and 1553 in 2018. this step; such articles have been discarded from the data aiming to only encircles relevant articles to the UF. The general research trend of the UF membrane persisted to manifest a surge in the number of academic articles published annually over the period studied for both platforms (Scopus and ScienceDirect) (Figure 1). This was due to the versatility of UF membranes have been reported in literature covering plentiful topics, as some will be discussed in the later sections.

Scopus is the world's largest abstract and citation database of peer-reviewed research literature. It contains over 20,500 titles from more than 5,000 international publishers. Scopus database delivers the most comprehensive view of the world's research output in the versatile fields of technology, science, social science, medicine, and arts and humanities. When Scopus was interrogated using "Ultrafiltration" as a search term in the title, abstract or keywords, it identified 14,882 articles in the period of interest. As shown in Figure 1(Left), there is a general trend of increasing research output, with 1264 publications in 2009 rising to 1402 in 2011, 1580 in 2013, 1659 in 2015, 1688
Figure 1: Yearly publications on Ultrafiltration identified by Scopus (Left) and ScienceDirect (Right).

In the meantime, Elsevier ScienceDirect delivers over 12 million publications from over 3,500 journals. When the search was repeated relying on ScienceDirect database, it identified a total of 4,547 publications, about one-third the number given by Scopus. The number of ultrafiltration

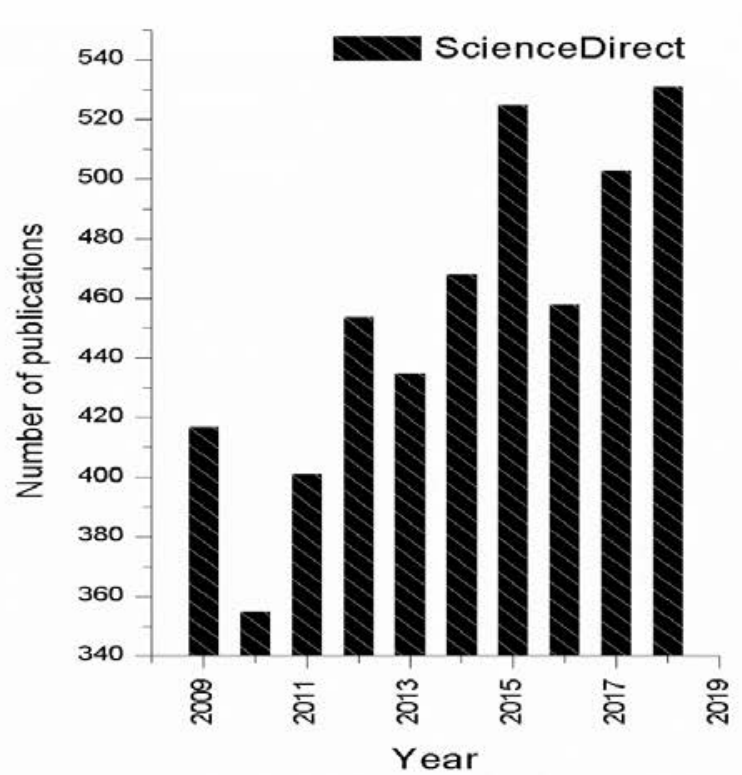
publications by year in ScienceDirect, as shown in Figure 1 (Right). The same general increase in research output can be seen, from 417 papers in 2009 increasing to 454 in 2012, 525 in 2015, and 
150531 in 2018. Herein it should be noted that even though both Scopus and ScienceDirect are scien151 tific literature databases owned by Elsevier, but ScienceDirect hosts the Elsevier content as full 152 text whereas Scopus comprises only abstracts and citation statistics concerning both Elsevier and 153 non-Elsevier content. And that is what could explain the variation in the number of articles been 154 published by both databases.

\section{$156 \quad 3$ General research trends since 2009}

157 As depicted in Figure 1, a general increasing trend in UF research can be seen since 2009. Ap158 proximately 4763 publications have been released within the specified research time. These are 159 dealt with review articles, research articles, book chapters, conference abstracts and reviews. 160 Among these, research articles were covering more than 95\% of the total publication types.

161 To elucidate the general area of research on UF membranes and processes, areas of research 162 specified for this study were used as additional search terms in the title, abstract or keywords when 163 searching ScienceDirect.

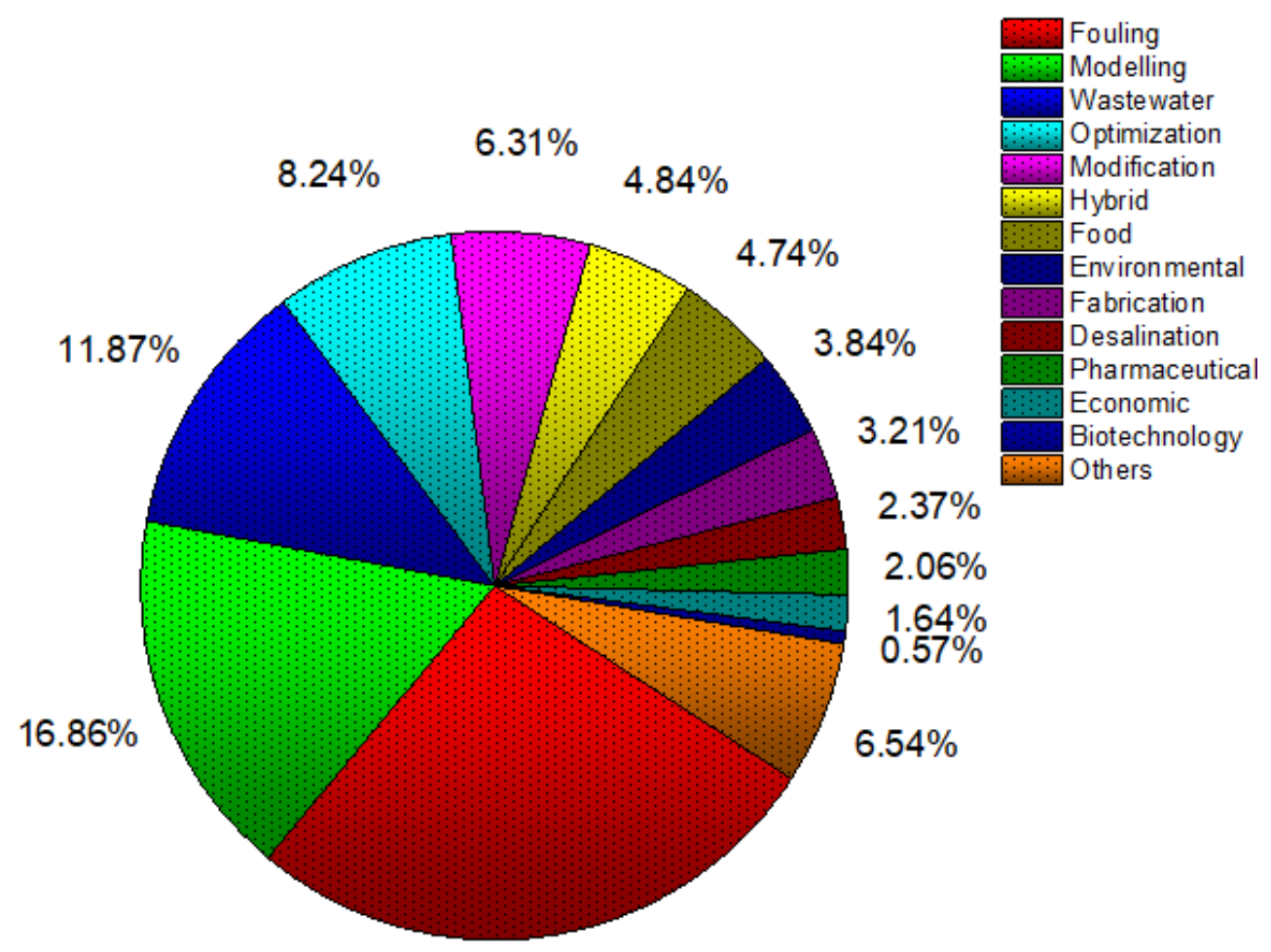

$26.9 \%$

164 Figure 2: Articles identified by additional keywords in ScienceDirect (2009-2018). 
Topics breakdown of articles from the total number of publications during the period between 2009-2018 is highlighted in Figure 2. The majority of the articles reviewed have dealt with fouling applications, with 1407 papers identified, this may, however, include publications that also cover other topics such as wastewater, membrane fabrication or modelling publications that have been devoted to mimic fouling behaviour of membranes. Membrane fouling applications total some $27 \%$ of the papers reviewed, the trend is then: modelling (17\%), wastewater (12\%), process opti172 mization (8\%), membrane modification (6\%), hybrid membrane processes (5\%), food (5\%), envi173 ronmental studies (4\%), membrane fabrication (3\%), desalination (2\%), pharmaceutical (2\%), 174 while the rest of the search terms returned about $9 \%$ for other applications. Given that wastewater, 175 environmental and desalination can befall in one section, given by "water processing", and since 176 membrane modification is a subset of membrane fabrication and can be grouped together [21], 177 water processing and membrane fabrication/modification would be the second and third research topics with $18 \%$ and $9 \%$ of total reviewed papers, respectively.

179 UF has a broad scope of applications, with research conducted out in the last ten years touching on a diverse range of subject areas. The top ten subject areas account for almost $93.7 \%$ of the total number of articles, with chemistry being the most active subject area for research, accounting for $18215.6 \%$ of the total, followed closely by the subject of chemical engineering. The remaining $6.3 \%$ 183 of papers are from subject areas such as energy, physics and astronomy, ...etc. Figure 3 elucidates 184 articles published for each of the top ten subject areas, as a percentage. It can be observed that the subject areas endue significant potential crossover-developments in polymers harnessed in membrane construction would be published in the field of chemistry and chemical engineering as well as environmental science, as these three subjects are covering $43.5 \%$ of the total articles. Many other subject areas indicate research into applications of UF, with medicine, biochemistry and 190 material science being identified as exceedingly active areas for research with $11 \%, 11 \%$ and $8.7 \%$, respectively. 


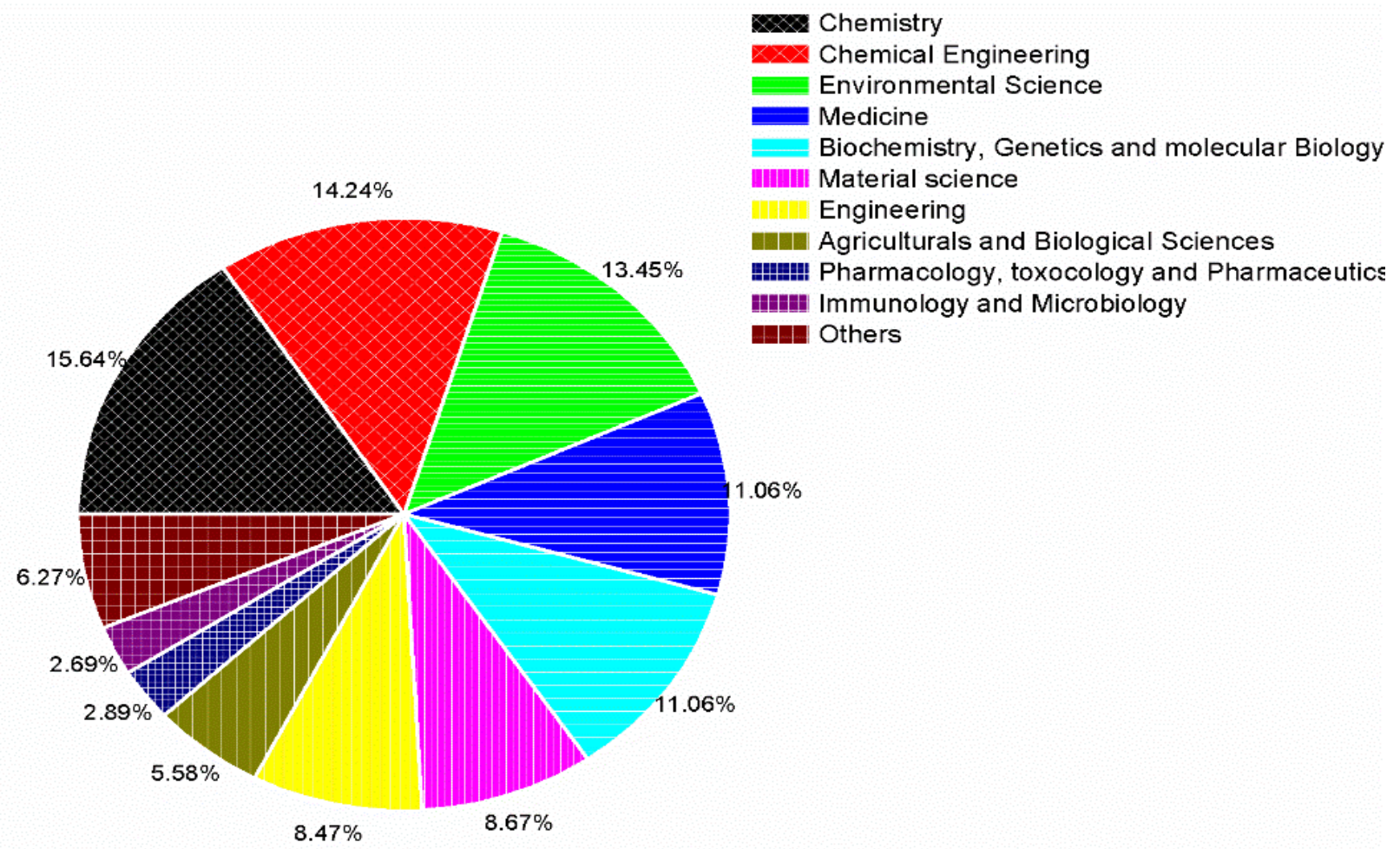

Figure 3: Number of articles published for the top ten subject areas involving ultrafiltration (as identified

192 by Scopus).

These broad applications of UF are reflected by the journals in which the articles were published. A closer look on top 10 journals publishing articles on UF discloses that both sources have identified almost same journals but at a different sequence, see Table 1- A (Supplementary file). The Journal of Membrane Science was the most active in publishing on UF for both Scopus and Science Direct platforms with 854 and 814 articles, accounting for $23.8 \%$ and $33.5 \%$ of the total in the 10-year period, respectively. For Scopus, Desalination and water treatment were the next most active with 683 articles followed by Desalination with 577, Separation and Purification (372), and Water Research (274) articles. In all, the top 10 journals published $24 \%$ of the total number of articles, with the remaining $76 \%$ of articles in journals each contributing less than $0.67 \%$ of the total. Whereas the contribution was $30.5 \%$ for the first 10 journals in ScienceDirect. In this context, among identified 14,882 articles in the period of interest, there were a number of the state of art reviews. The most ten cited titles and the number of their citations are listed in Table 1 below whereas Table 1- B (Supplementary file) elucidated the most productive institutions contributed to the publication's size of UF membranes research. These institutions participated in nearly $11.6 \%$ out of the total publications about UF research. 
210 Table 1: Highly cited reviews from 2009-2018, as identified by Scopus

\begin{tabular}{|c|c|c|c|}
\hline & Title of the review & $\begin{array}{l}\text { Cited } \\
\text { by }\end{array}$ & Ref. \\
\hline 1 & $\begin{array}{l}\text { Membrane fouling control in ultrafiltration technology for drinking water produc- } \\
\text { tion: A review }\end{array}$ & 414 & {$[24]$} \\
\hline 2 & Fouling of reverse osmosis and ultrafiltration membranes: A critical review & 316 & [25] \\
\hline 3 & Fouling and cleaning of ultrafiltration membranes: A review & 241 & [4] \\
\hline 4 & Humic substances fouling in ultrafiltration processes & 137 & [26] \\
\hline 5 & $\begin{array}{l}\text { Separation of functional macromolecules and micromolecules: From ultrafiltration } \\
\text { to the border of nanofiltration }\end{array}$ & 99 & [10] \\
\hline 6 & $\begin{array}{l}\text { Ultrafiltration in Food Processing Industry: Review on Application, Membrane } \\
\text { Fouling, and Fouling Control }\end{array}$ & 98 & [19] \\
\hline 7 & Role of electrostatic interactions during protein ultrafiltration & 55 & {$[27]$} \\
\hline 8 & Recycling of poultry process wastewater by ultrafiltration & 49 & [28] \\
\hline 9 & Metal removal from aqueous media by polymer-assisted ultrafiltration with chitosan & 40 & [29] \\
\hline 10 & $\begin{array}{l}\text { Removal of heavy metals from wastewater using micellar enhanced ultrafiltration } \\
\text { technique: A review }\end{array}$ & 38 & [30] \\
\hline
\end{tabular}

\section{Prevailing research trends (2009-2018)}

214 Among many topics, fouling of UF membranes has been an area of significant interest in the last 21510 years. It was the single largest area of research interest detected in this study, as mentioned in 216 the previous section. Undoubtedly, membrane fouling presented a serious obstacle restraining the 217 capability of ultrafiltration that could cause a higher operating cost due to increased energy de218 mand, more labour for maintenance, cleaning chemical costs, and shortening membrane lifespan. 219 Therefore, and unsurprisingly, calls for effective and efficient methods for its control and minimi220 sation has no approaching terminus on the horizon [4,31,32]. Figure 4, manifest the number of 221 published articles on this topic each year from 2009 to 2018. About 85-186 papers were published 222 annually, totalling to 1407 in the course of last decade. Apparently, this statistic review paper has 223 identified three periods of year-on-year growth from 2010-12, 2013-15, and 2016-17. The trend in 224 research on fouling is on an upward trajectory overall, from peaks of 118 papers in 2009, 128 in 225 2012, 181 in 2015, and 183 in 2017. Thus, the need for persistent expansion in this area can be 226 noticeably seen. 

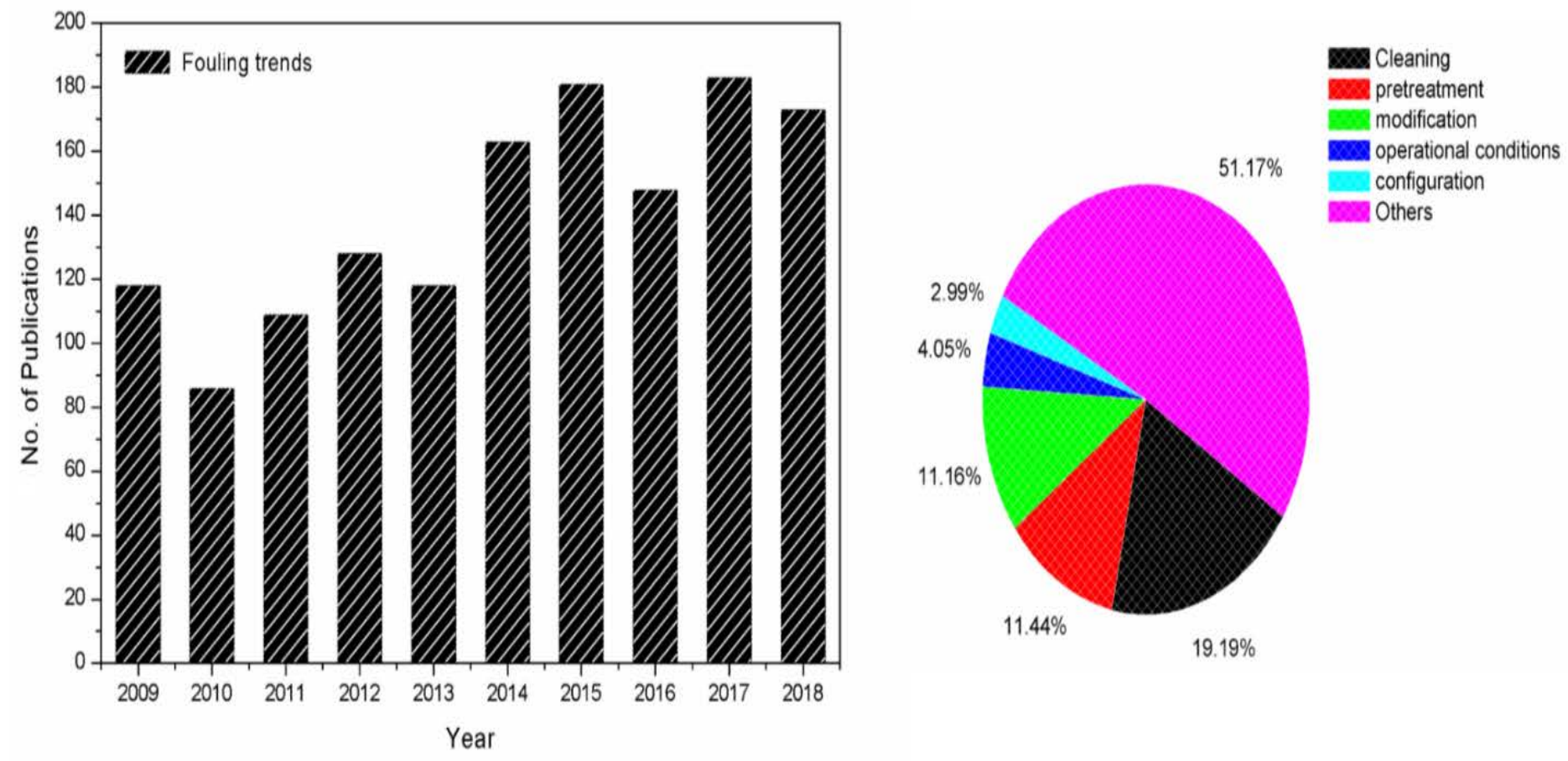

227 Figure 4: Research trend (2009-2018) on UF membrane fouling (Left), and main research themes on foul228 ing (Right), according to ScienceDirect.

A number of intercorrelated factors influences membrane fouling mechanism; process configuration, cleaning strategies, membrane types, material properties, operating conditions, and feed solution characteristics, are some among these methods. In spite of this, membrane cleaning is presently unavoidable and an essential part of membrane filtration in industry. Cleaning has to be

234 frequently incorporated during operation in order to minimise the permanent fouling and re-estab235 lish the efficiency [4,33]. Therefore, the majority of publications (about 20\%) was dealing with 236 multifaced membrane cleaning protocols [34-36]. Following this trend, the combination of re237 search publications on pretreatment and surface modification was more than $22 \%$ while research 238 about other factors such as; operational conditions and process configurations have manifested a 239 lower attractive research trend (Figure 4, Right).

240 Mathematical modelling in membrane operations for water treatment could be crucial to endow 241 useful data for the plant design and salutary prediction for the performance of the membrane water 242 treatment plant [37-40]. Variation of membrane processes (microfiltration, ultrafiltration, nanofil243 tration and reverse osmosis) necessitate dissimilar prediction models due to unlike transport mech244 anisms. With an appropriately reliable prediction model, operational membrane issues can be iden245 tified in advance. Hence, preventive actions can be taken to mitigate their impacts on long-term 
performance $[41,42]$. However, it still causes a struggle to fully understand the relationship between the many factors that affect the process. Therefore, modelling of ultrafiltration processes was the second largest area of research with a continued popular area of research. The annual number of published studies fluctuating around 88 from 2009 to 2018 (Figure 5). There appears to be an uptick in the past 4 years with the maximum annual number of papers released in 2015 at 108, and in excess of 100 papers published in 2018. In particular, these articles are concentrating on modelling solutes separation, fouling parameters, flow, and the influence of operational condi253 tions...etc [43-47].

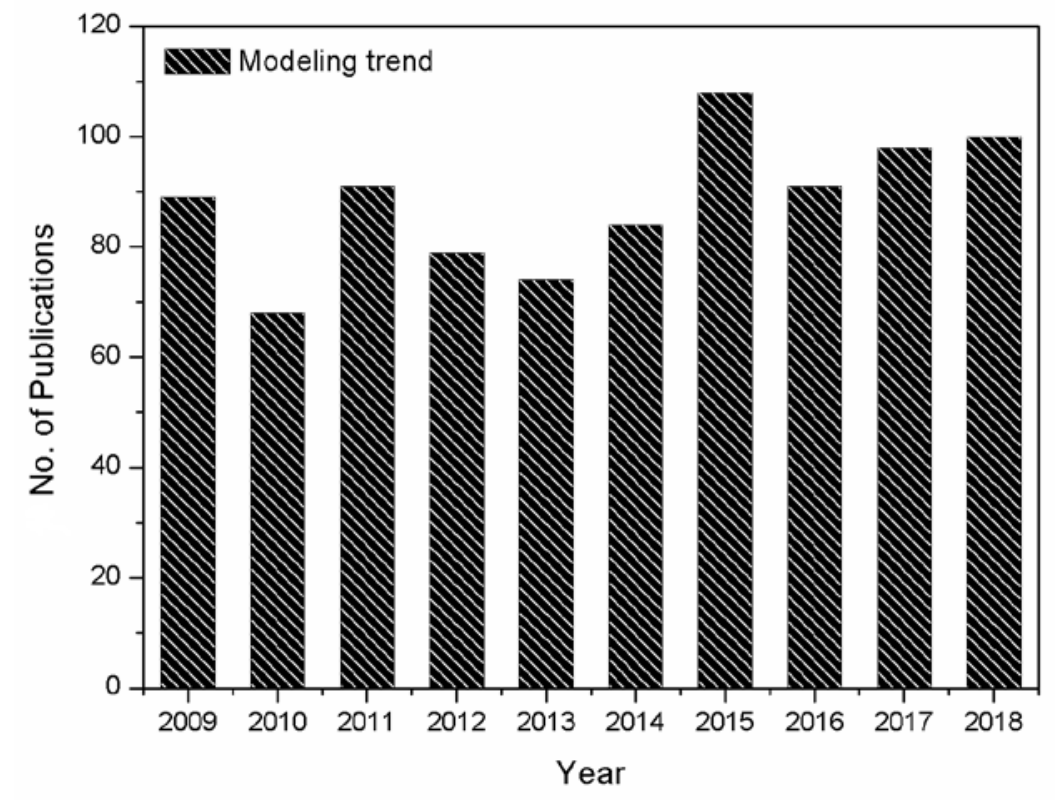

Figure 5: Research trend on ultrafiltration modelling (2009-2018), according to ScienceDirect.

255
More than 1.1 billion people on the planet do not have access to safe drinking water, while another 2.6 billion people had no proper sanitation [48]. A mounting population, an escalation in the requirement for resources, climate change, and pollution of accessible water resources are all applying exceptional difficulties on freshwater supplies around the world [49]. Clean water deficiencies will ultimately constrain economic growth and food supplies, while a shortage of water sanitation is coupled with appalling amounts of infant mortality in the developing world. With existing safe drinking water sources over-distributed, numerous regions of the world, are aiming to unconventional supplies such as seawater, brackish ground and surface water, and reclaimed wastewater. This explains why the third largest area of interest was dedicated to water processing.

Due to that, there is a steadily growing research interest related to ultrafiltration technology in wastewater and desalination applications. Unsurprisingly, this is associated with the development in the modern world where pollution prevention and control are a key objective of governments 
and is forcing industry and academia. Excluding 2009 and 2018, wastewater research on UF has manifested a gradual growth across the 10 year period, increasing from 41 publications in 2010 up to 59 in 2012, barring small spikes in 2015 and 2016, then71 articles in 2017 (Figure 6, Left). 2018 was a particularly strong year for wastewater research with a $35 \%$ increase in publications on the previous year, although this stands as an outlier from the general trend. Similarly, 2009 has witnessed more than $58 \%$ increase comparing to the subsequent year.

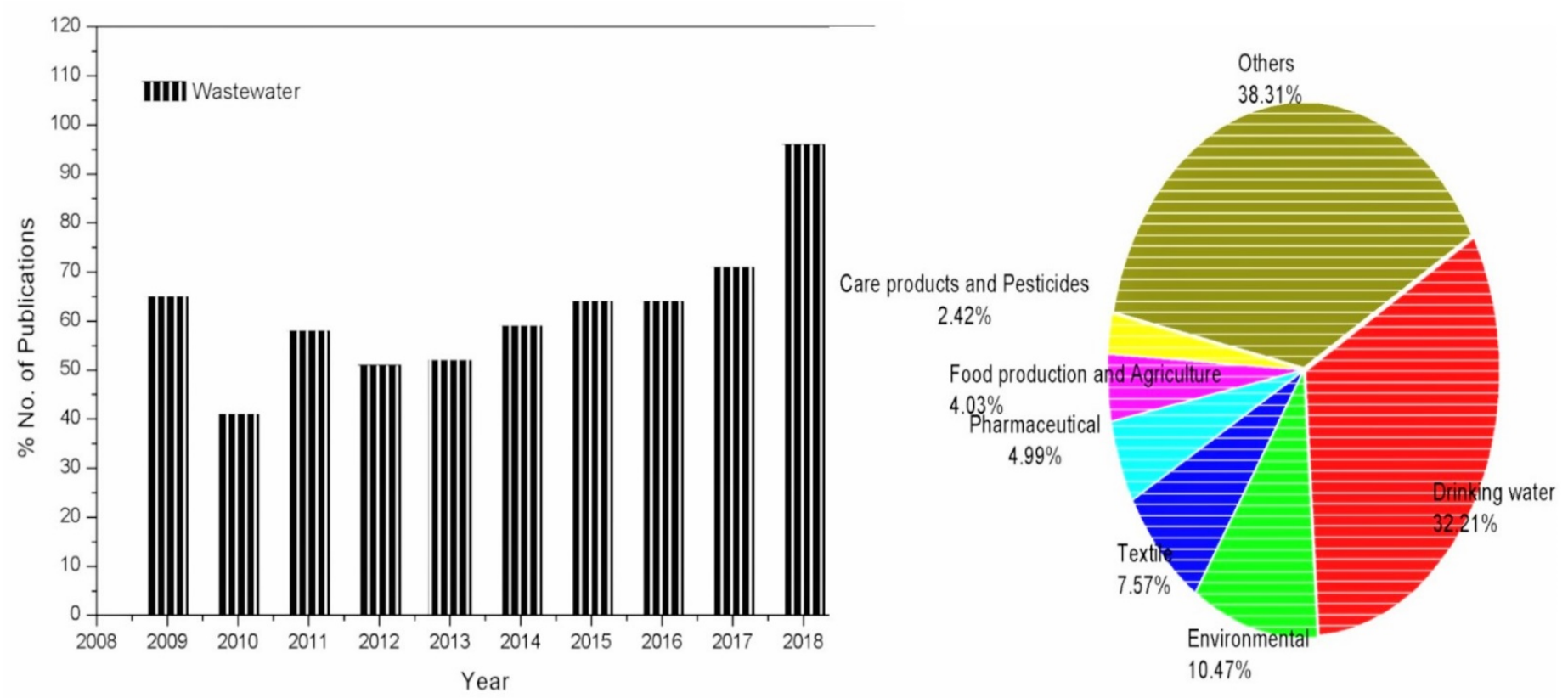

274 Figure 6: Research trend on wastewater applications from 2009-2018 (Left), application of UF for various 275 wastewater streams (Right), according to ScienceDirect.

Over the past several decades, the discharge of pollutants into the environment has greatly increased due to the swift industrial expansion and fast population growth. The water pollution warrants exceptional consideration, seeing as water quality correlates directly with the health of humans and wildlife [50]. These fairs have been translated into phenomenal efforts to overcome the water scarcity and quality issues, where more than $42 \%$ of wastewater applications research were dedicated to drinking water and environment. Amongst other contaminants in water, dyes from textile, paper, printing, and food industries have become a major threat to water security [51,52]. Textile wastewater is one of the most difficult waste streams in the industry to treat. The process consists of several unit operations such as dyeing, desizing, printing, sieving scouring, washing, bleaching, mercerizing, rinsing, carbonization, finishing and dyeing processes [53]. According to the China Environment Statistical Yearbook in 2015, the discharge of textile dyeing wastewater was about 1.84 billion tons annually in China, posing a serious danger to the aquatic ecosystem if not appropriately treated [54]. Food industries are commonly thought as the largest source of 
strong wastewater production which is categorised by high biological oxygen demand (BOD) and chemical oxygen demand (COD). Within the food industry, the dairy sector has the highest pollution in terms of water intake and characteristics of generated effluent [55]. Numerous recent studies have determined that emerging contaminants such as endocrine-disrupting compounds (EDCs), pesticides, disinfection by-products (DBPs), pharmaceutically active compounds (PhACs), and personal care products (PCPs) are found at trace concentrations in surface waters and the toxicity of many of these compounds can possibly develop harmful human, animal and ecological problems [56,57]. A quick breakdown to research trends, illustrated in Figure 6 (Right), shows that research into treating wastewater using UF membranes to produce drinking water is the largest researched sector (32\%), followed by environmental (10\%), with the textile (8\%) and pharmaceuticals (5\%) sectors following behind.

As mentioned earlier, fouling remains a major barrier limiting UF applications in treating various waters [58,59]. Figure 7 compares how fouling is a critical topic in wastewater research compared to other themes. According to the ScienceDirect platform, almost half of the wastewater related articles were dealing with fouling studies. The remaining half was discussing topics like 306 modelling (18.5\%), membrane fabrication and modification (9.18\%), and other topics (23.83\%). Table 2 below listed the top- 10 cited articles concerning fouling and wastewater topics.

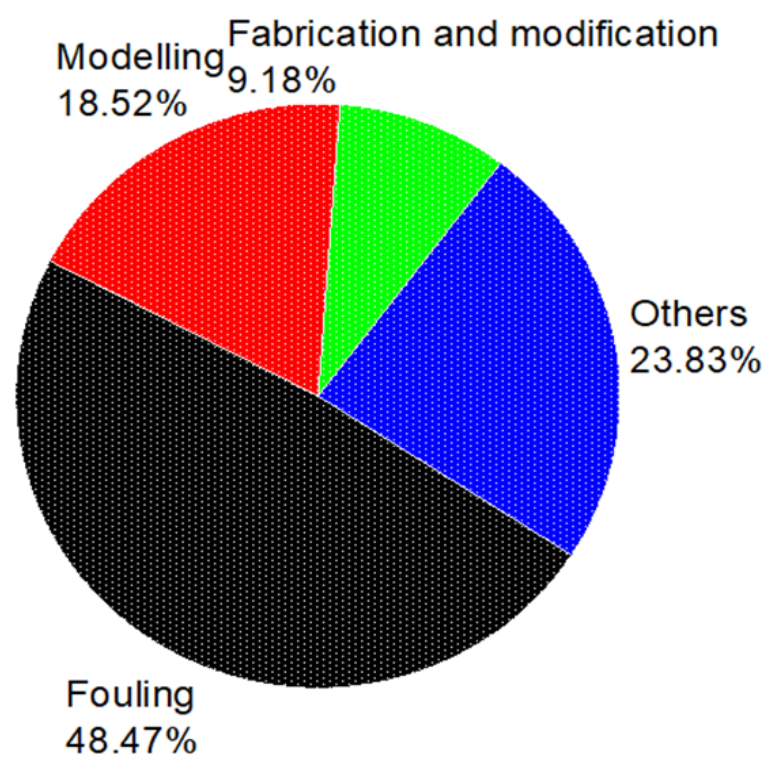

Figure 7: Research themes of wastewater (2009-2018), according to ScienceDirect. 


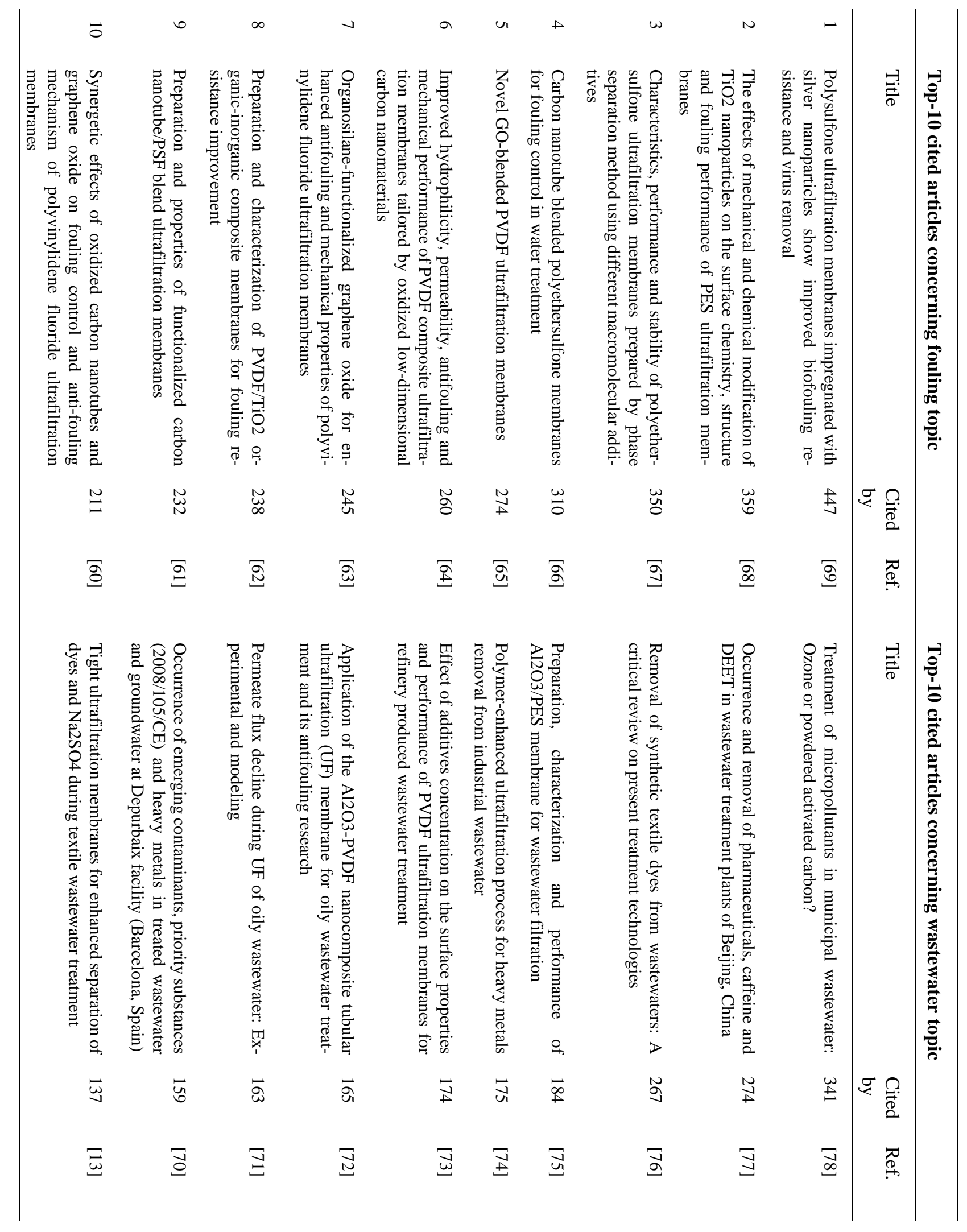


From the other hand, not all aspects of UF technology have witnessed an increasing trend. 312 Herein, the desalination topic was the research area where the UF had experienced decline or stag313 nation. Desalination applications are a niche within UF research especially for hybrid membrane 314 systems [79,80], and as such have a mixed level of publications over the last 10 years (Figure 8, 315 Left). 2015 was the most productive year, with 18 releases, whereas in 2011, 2012 and 2014 there 316 were only 9 articles each. Other years ranged from $10-16$ releases. With around $50 \%$ of the total 317 publications, identified with the keyword desalination, were concentrated in the last four years.
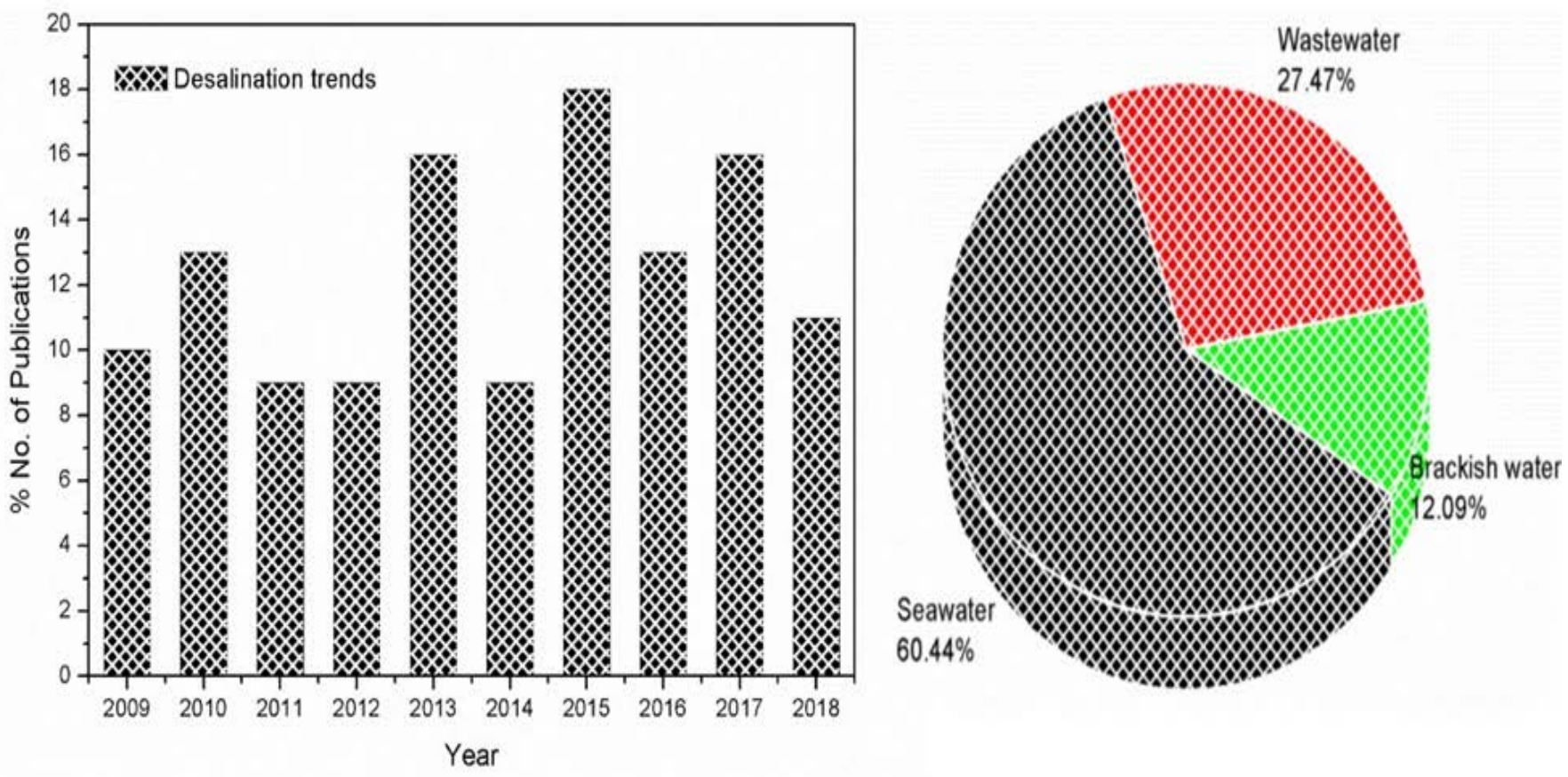
Figure 8: Research trend on ultrafiltration in desalination from 2009-2018 (Left), and Proportions of water feed streams desalinated utilising ultrafiltration (Right), according to ScienceDirect.

UF has been palpably employed as a pretreatment for desalination [81,82]. In difficult waters, 323 UF delivers superior water quality compared with conventional treatment due to the defined, very 324 fine pore structure. It delivers a continuously good filtrate quality independent of feed water quality 325 variability caused by, for instance, seasonal changes [83]. In the last decade, a number of papers 326 have reported research into desalination utilising ultrafiltration. Desalination for water treatment 327 was skewed between different types of feedwater, as shown in Figure 8 (Right), seawater being 328 the most popular with $60.5 \%$ of the releases, followed by wastewater (27.5\%) and lastly brackish 329 water (12\%). 
Environmental research has also exhibited a steady level of increase over the period investigated. The research saw a record surge in 2013 with 25 publications, more than the number from the previous year 2011 and 2012 combined (Figure 9). This increase was not sustained in the subsequent year, dropping down to 17 papers in 2014 before seeing a return to 24 papers in 2015, and marked an increase of 32 releases in 2016, 2017 and 2018.

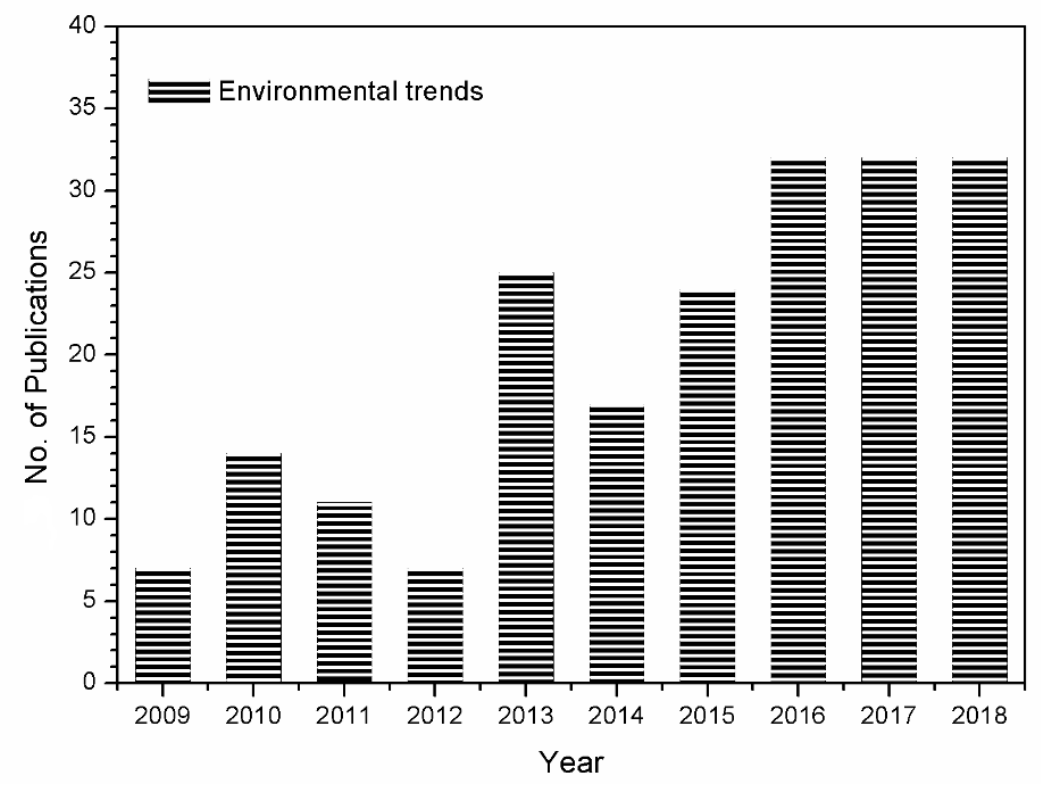

Figure 9: Research trend on environmental applications from 2009-2018

\section{Increasing research trends (2009-2018)}

As this review is performed, a number of research areas have disclosed a distinguished growing up trends in terms of publications during the years 2009-2018. These areas consisted of UF membrane fabrication and modification, food processing, hybrid membrane process, and design and 341 process optimization.

342 Although the total number of publications about membrane fabrication was small in 2009, a general sloping uptrend declares that the technique has quite evolved over the years, see Figure 10. Other than 2013, 2015 and 2016, which only had 10, 20 and 18 releases respectively, and belies the general trend. Publications have increased rapidly from 4 in 2009, 5 in 2010, 8 in 2011, 12 in 2012, then a jump to 22 papers in 2014 and 20 in 2015. The year 2017 appears to show the new higher level of research interest in membrane fabrication set to continue, with 35 releases. In 2018, 348 a slight drop was witnessed compared to the previous year but still strong when compared to the average values from the first 5 years in the period of observation.

Unsurprisingly, this evolution in the number of publications, about UF membrane fabrication and subsequent modification, is expected to continue aiming to enhance the overall UF membrane 
performance. The performance and properties of a membrane are heavily influenced by the techniques used for fabrication. However, phase inversion and solution wet-spinning were identified as the most common methods of UF membrane fabrication to endow with diverse membrane structures, properties and performance [84]. Along with that, the materials of which the membrane is constructed can also be advantageous for the targeted application. An example of this is the application of inorganic ceramic membranes for protein fractionation $[85,86]$. This material has superior thermal and mechanical properties over other types of commonly used membrane materials e.g. polymeric. Ceramic membranes can also be cleaned at extreme conditions, have a narrower pore size distribution allowing for more selective separation and offer the possibility for lower organic fouling [87]. Another important factor when assessing the viability of membrane material is the chemical nature of the membrane and the physiochemical environment of the solute. In this respect, $\mathrm{pH}$ and ionic strength determine the electrostatic interactions between the membrane and the molecules. Thus, permeation or transmission of a charged molecules through a membrane depends mostly on the electrostatic interactions between the molecules and the membrane and the relationship between the molecular size and the membrane pore size [88,89].

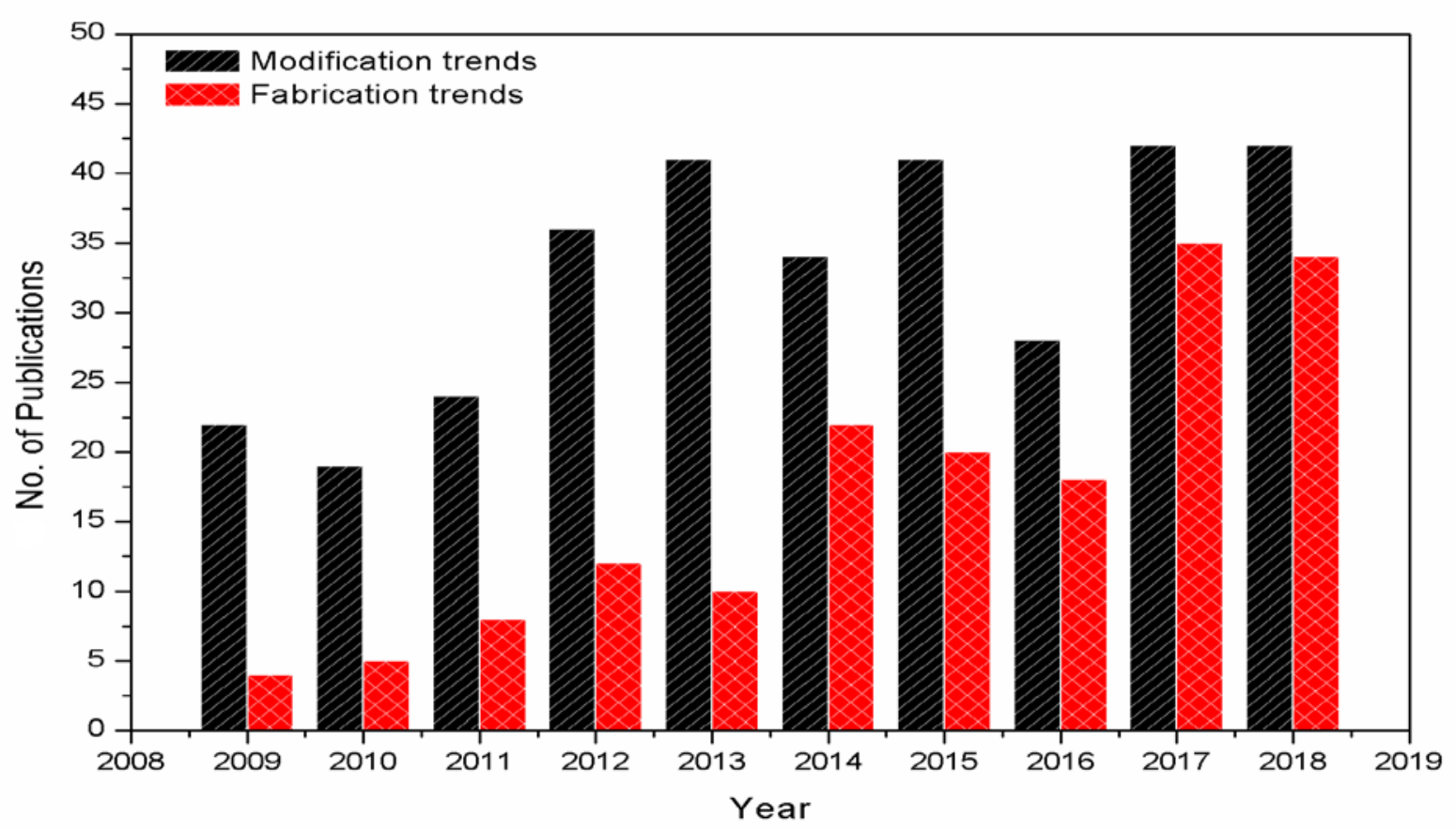

Figure 10: Research trend on membrane fabrication (Red), and Modification (Black) from 2009-2018.

In the meantime, research on UF membrane modification is a growing sustained area of attention with an excess of 22 papers published annually since 2009, with the overall pattern showing initial steady increase up to 41 publications in 2013, then flowed by a fluctuation period

372 with a local maximum of 41 papers in 2013 declining to 34 in 2014 and further still to 41 and 28 
373 in 2015 and 2016, respectively. Since then, there has been a steady number of papers year-on-year, 374 when 42 papers were published during 2017 and 2018. Table 3, listed the top-10 cited articles 375 concerning membrane fabrication and modification topic.

376 Table 3: Top-10 cited articles concerning membrane fabrication and modification topic (2009-2018).

\begin{tabular}{|c|c|c|c|}
\hline & Title of the article & $\begin{array}{l}\text { Cited } \\
\text { by }\end{array}$ & Ref. \\
\hline 1 & $\begin{array}{l}\text { The effects of mechanical and chemical modification of TiO2 nanoparticles on the } \\
\text { surface chemistry, structure and fouling performance of PES ultrafiltration mem- } \\
\text { branes }\end{array}$ & 359 & [68] \\
\hline 2 & $\begin{array}{l}\text { Characteristics, performance and stability of polyethersulfone ultrafiltration mem- } \\
\text { branes prepared by phase separation method using different macromolecular addi- } \\
\text { tives }\end{array}$ & 350 & [67] \\
\hline 3 & $\begin{array}{l}\text { Influence of polydopamine deposition conditions on pure water flux and foulant } \\
\text { adhesion resistance of reverse osmosis, ultrafiltration, and microfiltration mem- } \\
\text { branes }\end{array}$ & 243 & [90] \\
\hline 4 & $\begin{array}{l}\text { Synergetic effects of oxidized carbon nanotubes and graphene oxide on fouling } \\
\text { control and anti-fouling mechanism of polyvinylidene fluoride ultrafiltration } \\
\text { membranes }\end{array}$ & 211 & [60] \\
\hline 5 & $\begin{array}{l}\text { A bioinspired fouling-resistant surface modification for water purification mem- } \\
\text { branes }\end{array}$ & 206 & [91] \\
\hline 6 & $\begin{array}{l}\text { Effect of graphene oxide concentration on the morphologies and antifouling prop- } \\
\text { erties of PVDF ultrafiltration membranes }\end{array}$ & 198 & [92] \\
\hline 7 & $\begin{array}{l}\text { Sulfobetaine-grafted poly(vinylidene fluoride) ultrafiltration membranes exhibit } \\
\text { excellent antifouling property }\end{array}$ & 197 & [93] \\
\hline 8 & $\begin{array}{l}\text { Podocyte-secreted angiopoietin-like- } 4 \text { mediates proteinuria in glucocorticoid-sen- } \\
\text { sitive nephrotic syndrome }\end{array}$ & 196 & [94] \\
\hline 9 & $\begin{array}{l}\text { Preparation and characterization of poly(vinylidene fluoride) (PVDF) based ultra- } \\
\text { filtration membranes using nano } \gamma-\mathrm{Al}_{2} \mathrm{O}\end{array}$ & 192 & [95] \\
\hline 10 & $\begin{array}{l}\text { Highly hydrophilic polyvinylidene fluoride (PVDF) ultrafiltration membranes via } \\
\text { postfabrication grafting of surface-tailored silica nanoparticles }\end{array}$ & 185 & [96] \\
\hline
\end{tabular}

Membrane filtration, as a separation technique in the food industry, is becoming increasingly popular compared with other conventional methods such as affinity separation, chromatography and electrophoresis. While these methods have been successful in product purification, they are not suitable for large scale production due to their low throughput and high cost. On the other 383 hand, membranes have become a powerful tool for the recovery and purification of biomolecules 384 in large scale production. More specifically, ultrafiltration has become the most reliable technique 385 in the fractionation of specific compounds that are needed by the food, pharmaceutical and cos386 metic industries $[97,98]$. Similar to research trend on UF modification, food applications for UF 
have shown a strong increase for 2014 with 35 publications, about a threefold increase on the 12 papers published in 2009 (

Figure 11, Left). The overall trend is one of growth, but this is not maintained year-on-year, with the fluctuation period from 2015 to 2018, seeing 30 papers published in 2015, 32 in 2016, 27 in 2017 and 34 in 2018.
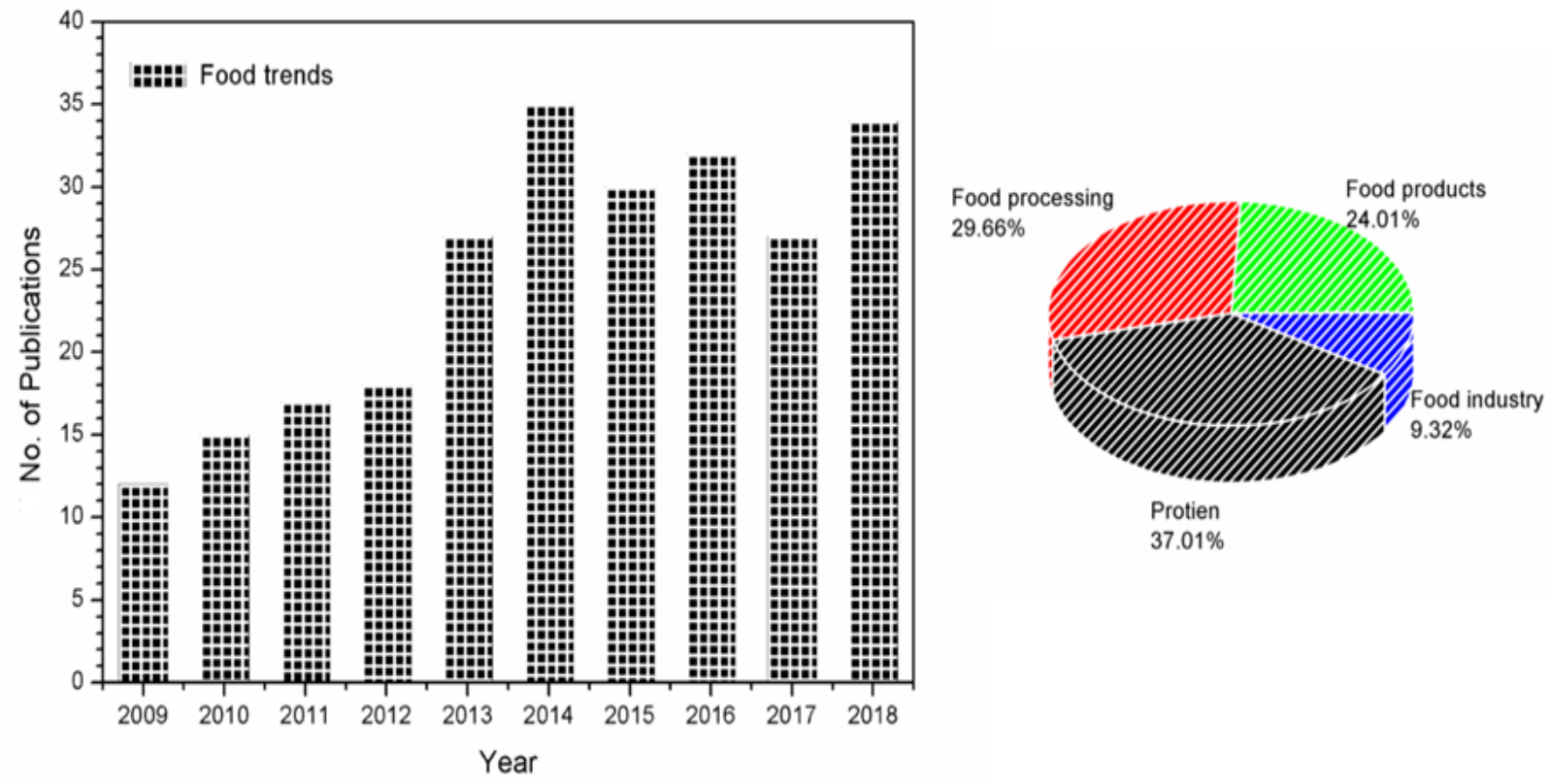

Figure 11: Research trend on food applications from 2009-2018 (Left), and breakdown of the food studies paper as a function of wide topics (Right).

A further breakdown for the food analysis into the most common topics, it was identified that protein, food processing, handling, industry and products were the widest areas of interest with the protein section leading in research. Some research papers overlapped their focuses on these topics

Figure 11, Right). Protein purification was characterized as the most important application in terms of ultrafiltration in the food industry (37\%), followed by food processing (29.7\%) and food products (24\%). Food industry contains the least share (9.3\%) of research performed in the last decade as seen, and this happens because the focus in the purification by a membrane lies as a pretreatment before other mechanisms take place, such as reactions, other purification stages, separation, etc. Based on the versatility acquired by the UF membrane processes over the years and their wide range of applications for the marketable food products, a four simple classification can be 
three topics contributed to about 59.5\% of the total number of articles within the adopted period 408 of the research.

409 This special interest paid for applications of UF in the food industry, as measured by the size 410 of publications, reflects the superior role of the UF technology. For instance; the properties of 411 biomolecules make them very sensitive to changes in temperature, pressure and with the addition 412 of additives that could change their chemical structure. Ultrafiltration membranes can be operated 413 isothermally and do not use any additives while pressure is controllable [88]. This compared with 414 other membranes of smaller sizes such as nanofiltration which require a higher driving force (pres415 sure) for the initial flux and this, in turn, would need a correspondingly high energy throughput. 416 Examples of biomolecules that can be isolated from the ultrafiltration technique in recently pub417 lished research are lycopene a carotenoid that gives certain fruits and vegetables their red colour. 418 This nutrient has been found to reduce the risk of cancers and heart disease making it a functional 419 food and a desirable product to extract [99]. Another biomolecule of use is palm oil due to its high 420 nutritional value and application in cosmetics. It is one of the fastest-growing industries in the 421 world; however, extraction of palm oil has resulted in a brown effluent which is known as palm 422 oil mill effluent. This effluent which is mainly entered through water bodies by eutrophication is 423 enriched with organic matter. Ultrafiltration can be employed to reclaim clean water from this 424 affluent and potentially be a solution to the global water crisis [100].

425 The concept of hybrid membrane processes has come a long way since the first inception. The 426 term hybrid or integrated membrane process refers to the integration of one or more membrane 427 processes with or without conventional unit operations to increase performance depending on the 428 type of feed and product quality required; with the main goal of these systems to increase the purity 429 of the product [101]. Hybrid membrane systems are also efficient in reducing the operating costs 430 and environmental pollution and hence make the overall process more efficient. Research on ap431 plications of hybrid UF processes has experienced a rising level of interest, with at least a threefold 432 increase in publications from 12 in 2010 to 38 in 2016 (Figure 12). The trend of strong upward 433 growth saw 23 articles in 2012, 29 in 2015, up to a maximum of 38 in 2016. Unexpectedly, this 434 surge was followed by a continuous decline within the past two years, with 36 and 25 articles in 4352017 and 2018, respectively. 


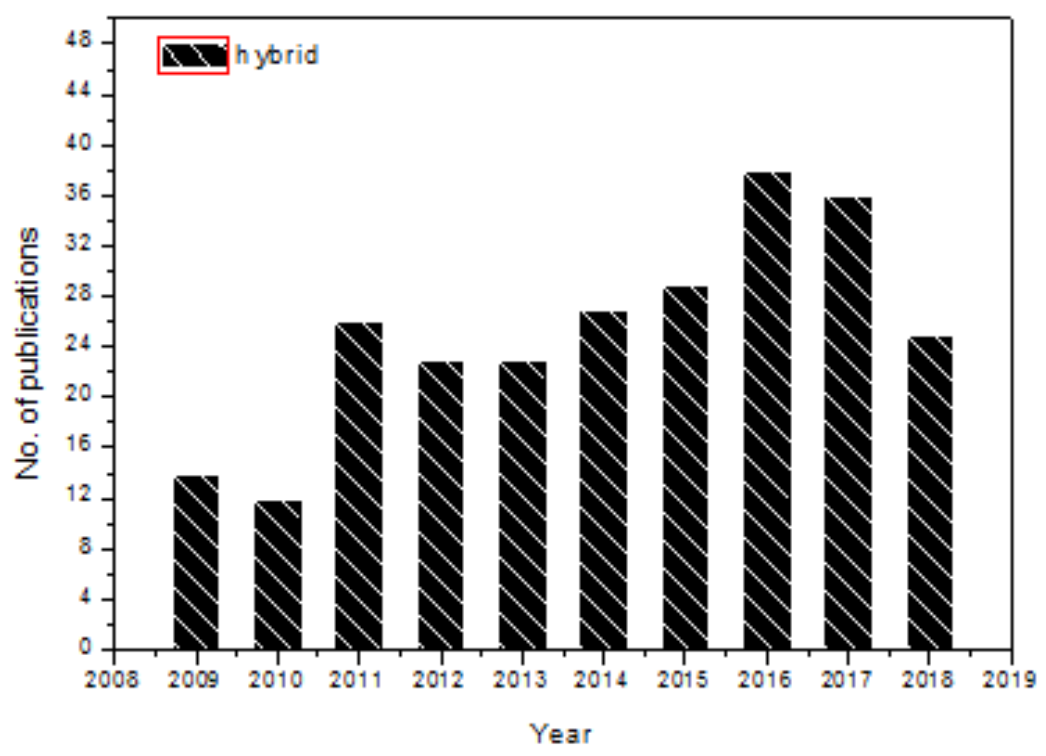

436 Figure 12: Research trend on hybrid UF membranes and processes (2009-2018).

438 At most, research articles published under the Optimization of UF membrane processes and 439 applications subsection were varied at most between enhancing operational parameters, cleaning 440 protocols, experimental design and fabrication conditions [102-105]. Virtually, optimization of 441 UF membrane processes has not shown a palpable surge in recent years (Figure 13). The only a 442 step-change has occurred between 2011-14 from 29-54 papers published annually. This annual 443 trend has continued around 51 \pm 3 publications since 2014, and onwards. 


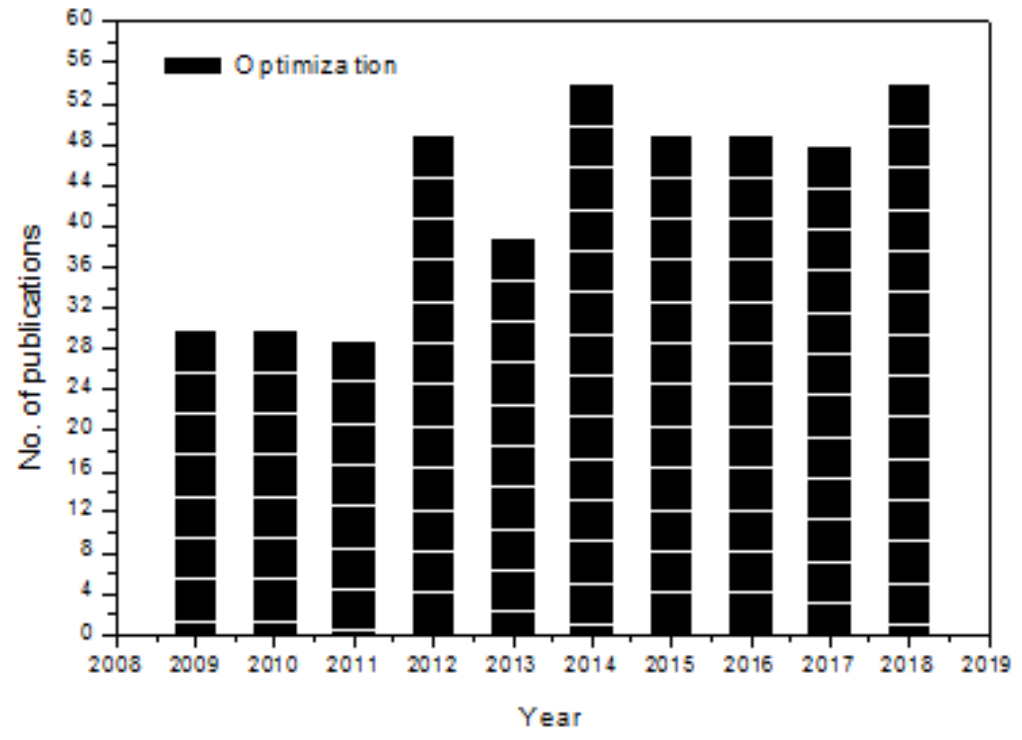

Figure 13: Research trends in design and process optimization (2009-2018).

\section{Potential trends in UF membrane filtration}

447 Huge advances in UF membrane processes and applications have been gained over since the first modern industrial UF membrane appeared in 1960 [106]. Even though that, there is still a long way to go with respect to membrane materials and modules, technology advancements, regulatory issues, applications, cost, system capacity and standardization [107]. As expounded earlier in section 3, fouling, modelling and wastewater, are rated as the major research areas while dominated half of the total publication's size. Excluding wastewater, a closer look at the top five UF research areas (Figure 3) discloses that the main theme of articles is concentrating on enhancing overall costs and technology advancements rather than the wide spectrum of UF applications in a variety of industrial sectors. Notwithstanding these research trends, many specific research areas were expected to endow greater research outputs if compared with their existing trends. One of these potential applications, that directly correlates to human health and needs to be further addressed, is medical applications. The concept of ultrafiltration has been widely employed in the medical industry as a component in implants [108], biosensors [109,110], diagnostic assays [111]and drug delivery systems [112,113]. Versatile molecular weight cut-off UF membranes have been utilized to retain microorganisms and constituents $[114,115]$. Also, patients with different pathologies undergo treatment including ultrafiltration applications with the goal of removal of toxins from the blood [116]. However, as can be seen in Figure 14A, there is no trend occurring in the medical aspect when focusing on ultrafiltration membranes. If 2012 was not taken into account, there would be only two or three papers published annually. One possible reason for this unreliability in paper research could be due to the irregularity in the ultrafiltration technique being applied to the 
human body. Therefore, there is always a need for further research outputs to develop functional 468 UF membranes that can meet the criteria. Similarly, extensive pore size ranges of UF membranes are available for use in the pharmaceutical industry. One of these applications is controlling endotoxin and pyrogen in the manufacturing of parenteral drug products to restrain adverse reactions in patients [117-119]. In addition to polypeptide and enzyme concentration along with a distinctive consistency and quality [120-123]. Despite the academic publications, about pharmaceutical products, did not exceed 107 review and research articles within the last decade, they revealed a clear increasing trend from 4 in 2009 to 18 publications in 2014 (Figure 14B). However, a decreasing trend was recorded after that and before the peak publication appears again in 2018. Research activities need exceptional efforts for developing high-performance UF membranes combines high permeability and maximum selectivity. Also, the reliability of bio-macromolecules fractionation that often hindered by severe fouling. A common example in the pharmaceutical industry is the protein separation. A workable fractionation process is only possible for proteins with significant variation in their molecular weights [124]. Therefore, surface modification of these membranes through enhancing electrostatic repulsions could bestow practical solutions to the selectivity issues, especially for proteins having convergent molecular weights.

Another area which necessitates further attention is the application of UF technique in the textile industry. Herein, UF main functions are through concentrating dye and effluent treatment for recovering valuable products and water reuse purposes in textile manufacturing processes [125]. Figure 14C contains the data of the textile research trend changes in the last 10 years. Even though interests in the application of UF in the textile industry was almost double of that been witnessed in medicine, there was somehow an erratic trend in publications rate as has been illustrated, and the general trend is one of a slight increase. This could be attributed to the moderate dye retention of UF membranes. This is imperfect for dye recovery where a significant quantity of dye can pass through porous UF membranes, leading to a low recovery for dye during a diafiltration process [126]. Notwithstanding that, tight UF membranes have demonstrated to be a stand-alone alternative to nanofiltration membranes to endow an effective fractionation of dye and divalent salts in the direct treatment of textile wastewater with high-salinity [13,127].

One of the least research fields of ultrafiltration was applied in the petroleum sector. The petroleum industry is one of the fastest-growing sectors, and it significantly participates in the economic growth of developing countries [128]. Particular attention has been paid recently on the development of high-performance low-cost wastewater treatment technologies [129]. Virtually, produced oily wastewater composes a large volume of very complex wastewater generated from different sectors. This includes; petroleum hydrocarbons, phenol, mercaptans, oil and grease, sulphide, ammonia and other organic compounds that necessitates an efficient demulsification [130]. In this context, low-pressure membranes (UF and MF) have demonstrated their eligibility for the reuse and treatment of flowback and produced water resulted from unconventional oil and gas resources e.g., shale gas and oil plays. Their share has exceeded 22\% among other membrane-based technologies [131]. The possibility of presenting the UF/MF membranes as a compact configuration 
stands behind their feasibility where space is very limited, which makes them ideal for on-site and mobile treatment. Herein, UF/MF membranes could remove most suspended solids, turbidity, grease, oil and a fraction of organic compounds. As seen in Figure 14D, no relationship in terms of a number of research papers produced has been observed for each year. This happens because the petroleum industry covers materials that are much larger than the possible exclusion done by ultrafiltration, which only gives the opportunity for pre-treatment of materials instead of ultrafiltration working as the main method of purification. If the ultrafiltration section or the nanofiltration section were to be done separately, this particular application in the industry would not have been as successful, so the combination of a hybrid system could maximize the operability of the process. In a recent study carried by Moslehyani et al. [132], the design and performance of a hybrid system, comprising a photocatalytic reactor followed by a UF membrane cell, was evaluated against petroleum refinery wastewater. Interesting results have been displayed due to the over 99\% rejection and exceptional anti-fouling characteristics.

Even though water processing was found as a dominant research area in UF technology here in this review, further research outputs about several aspects are necessitated. One of these approaches is the applications of UF hybrid membrane systems in desalination plants, as an alternative to standardized conventional separation technologies. The felicitous operation of a seawater desalination plant relies mainly on the competence of the pretreatment system utilized for consistent production of permeate in the subsequent RO process [133]. Thus, selection between conventional and membrane-based pretreatment is increasingly becoming tricky to make a prudent decision [81]. Busch et al. claimed that about 3.4 million $\mathrm{m}^{3} /$ day of UF pretreatment capacity was installed in seawater RO plants in 2010. However, the recent drivers for UF technology selection have been also changed where more emphasis is given to environmental aspects. This includes the capability of UF to decrease chemical consumption and sludge quantities of the plants. Although the greater operating cost of UF when being compared with other conventional pre-treatment is still the main obstacle [134], there are many signs indicates their becoming increasingly cost-competitive [135-137].

Based on the aforementioned examples above, it is can be inferred that the inevitable fouling and degrading of UF membranes are the major obstacles that limit their applications, especially for treating some complex feeds. This has gone hand by hand with economical considerations. Fouling's level is dominated by feed and membrane characteristics, regardless of operation hydrodynamics. Membrane's material harnessed for one application may not fit another. The versatility of feed compositions makes each UF membranes material and/or structure behaves differently in terms of their permeability-selectivity trade-off. Thus, surface characteristics, (e.g. hydrophilicity, type of functional group, charge, roughness, pore size and porosity), may endow unlike resistivity to membrane's ageing and fouling in the short time. One possible solution could be through employing functional UF membranes targeting a specific application instead of being inclusive. For instance, revising the surface characteristics of the designated membrane to enhance their selec- 
544 tivity, and/or to withstand harsh cleaning chemicals or to have antibacterial characteristics. An545 other promising solution, that needs to be further addressed, is through focussing on hybrid mem546 brane-based processes to ensure that UF membrane avail can outweigh their cost. As a pretreat547 ment step in the petroleum industry, the potential of hybrid UF membrane system should be further 548 considered in the competition with other conventional demulsification techniques. Nevertheless, 549 efforts are expected to continue towards the contribution of UF technology for the future of sea550 water desalination plants.
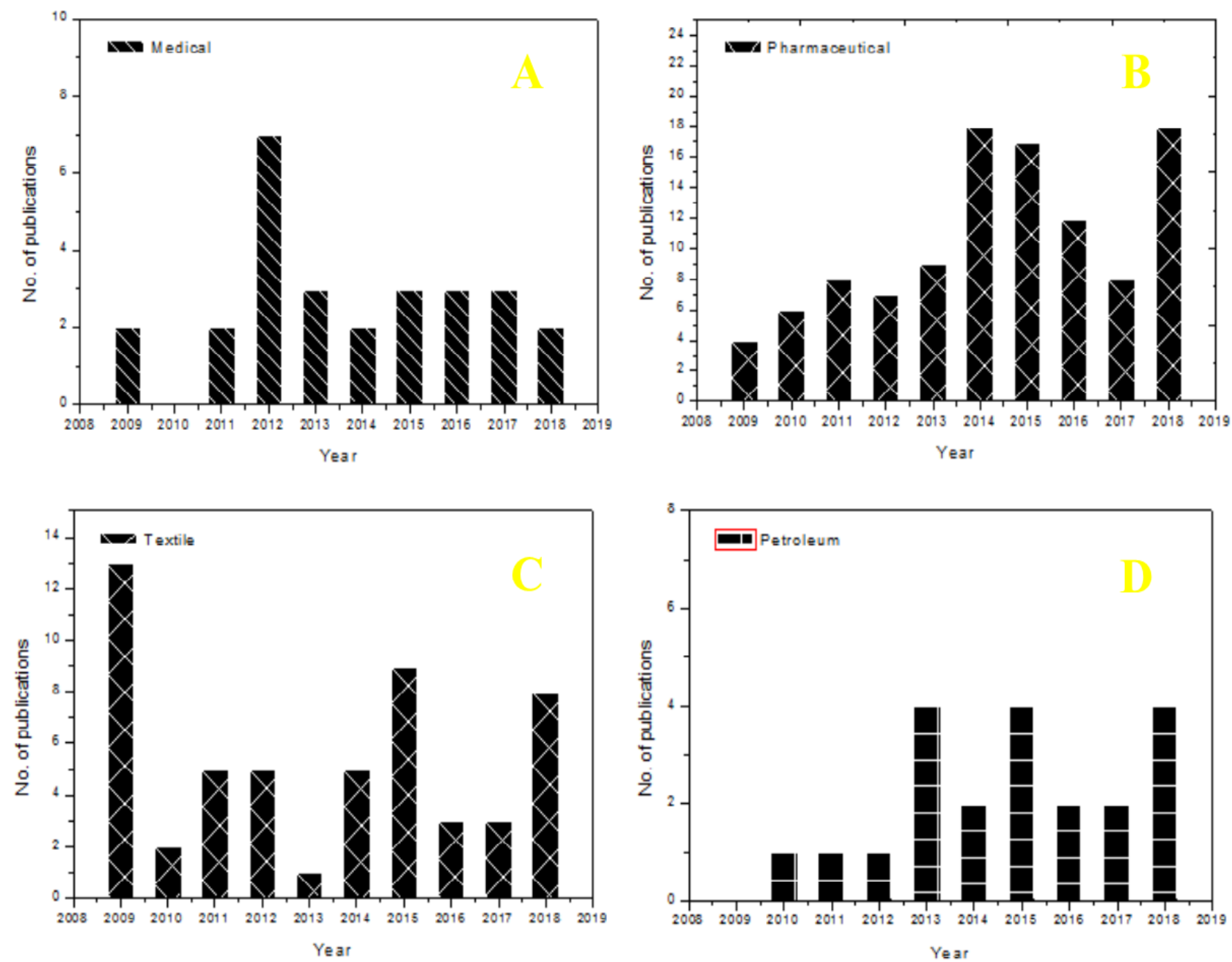

551 Figure 14: Research trends of UF membrane applications from 2009-2018 for (A) Medical, (B) Pharma552 ceutical, (C) Textile, and (D) Petroleum industry. 


\section{Conclusions}

555 As measured by the scientific database platforms, UF membranes and processes are gaining fea556 tured attention inside the scientific research community. An indispensable role has been played in 557 a wide range of applications, including; food, beverage, healthcare products, bioengineering, in558 dustrial and municipal water, desalination and drinking water. It should be noted here that the 559 major concern was to monitor the size of research interest in UF membranes and processes over 560 the past decade. And the current statistical investigation has presented a rough estimation review 561 since many topics are overlapped with others. Excluding 2009, the number of academic papers 562 published has been steadily increased from 355 paper in 2010, 468 in 2014 to 531 in 2018, as 563 identified by the ScienceDirect platform. About $43 \%$ of the total number of publications (4547 564 articles) lay within three major scopes; chemistry, chemical engineering and environmental. 565 Among 120 detected scientific journals, the Journal of Membrane Science was the leading one, 566 comprising about $18 \%$ of the total publications. The heading topics have been discussed were 567 concentrating on fouling, modelling and wastewater, and corresponded to $27 \%, 17 \%$, and $12 \%$ of 568 the total articles reviewed, respectively. To a lesser extent, other topics such as; membrane fabri569 cation and modification, environmental applications, food and pharmaceutical had conspicuous 570 increasing trends, particularly within the few past years. A closer look from a wide-angle enables 571 the reader to infer that the fouling was the major concern to confine the UF applications in some 572 fields, however, combining the technology with other separation tools (hybrid separation systems) 573 could endow further advantage to outweigh the technology. Based on the available statistics, there 574 is no doubt, in the recent future, that research community will persist to enhance the overall per575 formance of UF technology and to expand their application prospects. Ultimately, establishing 576 growth opportunities for UF membrane filtration in a wide spectrum of industries.

579 Nomenclatures

$\begin{array}{ll}\text { UF } & \text { Ultrafiltration } \\ \text { MWCO } & \text { Molecular weight cut-off } \\ \text { BOD } & \text { Biological oxygen demand. } \\ \text { COD } & \text { Chemical oxygen demand } \\ \text { EDCs } & \text { Endocrine-disrupting compounds } \\ \text { DBPs } & \text { Disinfection By-products } \\ \text { PCPs } & \text { Personal care products } \\ \text { PhACs } & \text { Pharmaceutically active compounds } \\ \text { MF } & \text { Microfiltration }\end{array}$




\section{References}

582 [1] A.F. Ismail, K.C. Khulbe, T. Matsuura, Introduction, in: Gas Sep. Membr., Springer International Publishing, Cham, 2015.

[2] I.N. Widiasa, G.R. Harvianto, H. Susanto, T. Istirokhatun, T.W. Agustini, Searching for ultrafiltration membrane molecular weight cut-off for water treatment in recirculating aquaculture system, J. Water Process Eng. 21 (2018) 133-142.

[3] Industryarc, RO and UF Membranes Market - Forecast(2019 - 2024), Hyderabad, Report Code: CMR 0006, 2019. https://www.industryarc.com/Report/1288/RO-and-UFMembranes-Market-report.html\%0A\%0A.

[4] X. Shi, G. Tal, N.P. Hankins, V. Gitis, Fouling and cleaning of ultrafiltration membranes: A review, J. Water Process Eng. 1 (2014) 121-138.

[5] K.M. Barry, T.G. Dinan, P.M. Kelly, Pilot scale production of a phospholipid-enriched dairy ingredient by means of an optimised integrated process employing enzymatic hydrolysis, ultrafiltration and super-critical fluid extraction, Innov. Food Sci. Emerg. Technol. 41 (2017) 301-306.

[6] X. Zhou, J. Liang, Y. Zhang, H. Zhao, Y. Guo, S. Shi, Separation and purification of $\alpha-$ glucosidase inhibitors from Polygonatum odoratum by stepwise high-speed counter-current chromatography combined with Sephadex LH-20 chromatography target-guided by ultrafiltration-HPLC screening, J. Chromatogr. B. 985 (2015) 149-154.

[7] W. Zou, K.R. Davey, An integrated two-step Fr 13 synthesis - demonstrated with membrane fouling in combined ultrafiltration-osmotic distillation (UF-OD) for concentrated juice, Chem. Eng. Sci. 152 (2016) 213-226.

[8] S. Lee, M. Ihara, N. Yamashita, H. Tanaka, Improvement of virus removal by pilot-scale coagulation-ultrafiltration process for wastewater reclamation: Effect of optimization of $\mathrm{pH}$ in secondary effluent, Water Res. 114 (2017) 23-30.

[9] M.C. Tarifa, J.E. Lozano, L.I. Brugnoni, Disinfection efficacy over yeast biofilms of juice processing industries, Food Res. Int. 105 (2018) 473-481.

[10] C.M. Galanakis, Separation of functional macromolecules and micromolecules: From ultrafiltration to the border of nanofiltration, Trends Food Sci. Technol. 42 (2015) 44-63.

[11] Z. Zhu, F. Yuan, Z. Xu, W. Wang, X. Di, F.J. Barba, W. Shen, M. Koubaa, Stirring-assisted dead-end ultrafiltration for protein and polyphenol recovery from purple sweet potato juices: Filtration behavior investigation and HPLC-DAD-ESI-MS2 profiling, Sep. Purif. Technol. 169 (2016) 25-32.

[12] J.S.S. Yadav, S. Yan, C.M. Ajila, J. Bezawada, R.D. Tyagi, R.Y. Surampalli, Food-grade single-cell protein production, characterization and ultrafiltration recovery of residual fermented whey proteins from whey, Food Bioprod. Process. 99 (2016) 156-165.

[13] J. Lin, W. Ye, M.C. Baltaru, Y.P. Tang, N.J. Bernstein, P. Gao, P. Luis, Tight ultrafiltration membranes for enhanced separation of dyes and $\mathrm{Na} 2 \mathrm{SO} 4$ during textile wastewater treatment, J. Memb. Sci. 514 (2016) 217-228. 
[14] S.L. Dashtban Kenari, B. Barbeau, Understanding ultrafiltration fouling of ceramic and polymeric membranes caused by oxidized iron and manganese in water treatment, J. Memb. Sci. 516 (2016) 1-12.

[15] G.J. Gentile, M.C. Cruz, V.B. Rajal, M.M. Fidalgo de Cortalezzi, Electrostatic interactions in virus removal by ultrafiltration membranes, J. Environ. Chem. Eng. 6 (2018) 1314-1321.

[16] B. Santra, S. Kar, S. Ghosh, S. Majumdar, An Integrated Process Development for Treatment of Textile Effluent Involving Ceramic Membrane-Driven Ultrafiltration and Biosorption, in: Waste Water Recycl. Manag., Springer Singapore, 2019: pp. 75-84.

[17] R. Lu, C. Zhang, M. Piatkovsky, M. Ulbricht, M. Herzberg, T.H. Nguyen, Improvement of virus removal using ultrafiltration membranes modified with grafted zwitterionic polymer hydrogels, Water Res. 116 (2017) 86-94.

[18] R. Rohani, M. Hyland, D. Patterson, A refined one-filtration method for aqueous based nanofiltration and ultrafiltration membrane molecular weight cut-off determination using polyethylene glycols, J. Memb. Sci. 382 (2011) 278-290.

[19] A.W. Mohammad, C.Y. Ng, Y.P. Lim, G.H. Ng, Ultrafiltration in Food Processing Industry: Review on Application, Membrane Fouling, and Fouling Control, Food Bioprocess Technol. 5 (2012) 1143-1156.

[20] D. Lamb, The Uses of Analysis: Rhetorical Analysis, Article Analysis, and the Literature Review, Acad. Writ. Tutor. (2014) 23.

[21] D.L. Oatley-Radcliffe, M. Walters, T.J. Ainscough, P.M. Williams, A.W. Mohammad, N. Hilal, Nanofiltration membranes and processes: A review of research trends over the past decade, J. Water Process Eng. 19 (2017) 164-171.

[22] S.F. Anis, R. Hashaikeh, N. Hilal, Microfiltration membrane processes: A review of research trends over the past decade, J. Water Process Eng. 32 (2019).

[23] M. Tober, PubMed, ScienceDirect, Scopus or Google Scholar - Which is the best search engine for an effective literature research in laser medicine?, Med. Laser Appl. 26 (2011) 139-144.

[24] W. Gao, H. Liang, J. Ma, M. Han, Z. lin Chen, Z. shuang Han, G. bai Li, Membrane fouling control in ultrafiltration technology for drinking water production: A review, Desalination. 272 (2011) 1-8.

[25] M.F.A. Goosen, S.S. Sablani, H. Al-Hinai, S. Al-Obeidani, R. Al-Belushi, D. Jackson, Fouling of reverse osmosis and ultrafiltration membranes: A critical review, Sep. Sci. Technol. 39 (2004) 2261-2297.

[26] I. Sutzkover-Gutman, D. Hasson, R. Semiat, Humic substances fouling in ultrafiltration processes, Desalination. 261 (2010) 218-231.

[27] M.M. Rohani, A.L. Zydney, Role of electrostatic interactions during protein ultrafiltration, Adv. Colloid Interface Sci. 160 (2010) 40-48.

[28] R.Y. Avula, H.M. Nelson, R.K. Singh, Recycling of poultry process wastewater by ultrafiltration, Innov. Food Sci. Emerg. Technol. 10 (2009) 1-8. 
[29] G. Crini, N. Morin-Crini, N. Fatin-Rouge, S. Déon, P. Fievet, Metal removal from aqueous media by polymer-assisted ultrafiltration with chitosan, Arab. J. Chem. 10 (2017) S3826S3839.

[30] A.A. Mungray, S. V. Kulkarni, A.K. Mungray, Removal of heavy metals from wastewater using micellar enhanced ultrafiltration technique: A review, Cent. Eur. J. Chem. 10 (2012) 27-46.

[31] N.F. Razali, A.W. Mohammad, N. Hilal, Effects of polyaniline nanoparticles in polyethersulfone ultrafiltration membranes: Fouling behaviours by different types of foulant, J. Ind. Eng. Chem. 20 (2014) 3134-3140.

[32] I.N.H.M. Amin, A.W. Mohammad, M. Markom, L.C. Peng, N. Hilal, Flux decline study during ultrafiltration of glycerin-rich fatty acid solutions, J. Memb. Sci. 351 (2010) 75-86.

[33] S. Al Aani, A. Haroutounian, C.J. Wright, N. Hilal, Thin Film Nanocomposite (TFN) membranes modified with polydopamine coated metals/carbon-nanostructures for desalination applications, Desalination. 427 (2018) 60-74.

[34] M. Qasim, N.N. Darwish, S. Mhiyo, N.A. Darwish, N. Hilal, The use of ultrasound to mitigate membrane fouling in desalination and water treatment, Desalination. 443 (2018) 143-164.

[35] M.T. Alresheedi, O.D. Basu, B. Barbeau, Chemical cleaning of ceramic ultrafiltration membranes - Ozone versus conventional cleaning chemicals, Chemosphere. 226 (2019) 668-677.

[36] O. Ferrer, B. Lefèvre, G. Prats, X. Bernat, O. Gibert, M. Paraira, Reversibility of fouling on ultrafiltration membrane by backwashing and chemical cleaning: differences in organic fractions behaviour, Desalin. Water Treat. 57 (2016) 8593-8607.

[37] F.E. Ahmed, R. Hashaikeh, A. Diabat, N. Hilal, Mathematical and optimization modelling in desalination: State-of-the-art and future direction, Desalination. 469 (2019).

[38] S. Al Aani, T. Bonny, S.W. Hasan, N. Hilal, Can machine language and artificial intelligence revolutionize process automation for water treatment and desalination?, Desalination. 458 (2019) 84-96.

[39] A. Charfi, H. Jang, J. Kim, Modelling tool to assess membrane regeneration by periodical hydraulic cleaning and fouling control in pressurized membrane process for surface water treatment, Environ. Earth Sci. 78 (2019).

[40] A. Zehra, M.M.A. Khan, Rafiuddin, Mathematical modelling of cobalt based composite membrane using TMS method; confirming its efficiency and selectivity, J. Polym. Res. 25 (2018).

[41] W.L. Ang, A.W. Mohammad, Mathematical modeling of membrane operations for water treatment, in: Adv. Membr. Technol. Water Treat., Woodhead Publishing, 2015: pp. 379407.

[42] D.L. Oatley-Radcliffe, S. Al-Aani, P.M. Williams, N. Hilal, Mass Transport in Porous Liquid Phase Membranes, in: Membr. Charact., Elsevier, 2017: pp. 337-358. 
[43] P. Pal, R. Kumar, S. Banerjee, Purification and concentration of gluconic acid from an integrated fermentation and membrane process using response surface optimized conditions, Front. Chem. Sci. Eng. 13 (2019) 152-163.

[44] S.M. Ali, J.E. Kim, S. Phuntsho, A. Jang, J.Y. Choi, H.K. Shon, Forward osmosis system analysis for optimum design and operating conditions, Water Res. 145 (2018) 429-441.

[45] S. Bajpai, R.M. Rajendran, S. Hooda, Modeling the performance of HPA membrane for sulfate ion removal from Ternary ion system, Korean J. Chem. Eng. 36 (2019) 1648-1656.

[46] A. Charfi, E. Park, M. Aslam, J. Kim, Particle-sparged anaerobic membrane bioreactor with fluidized polyethylene terephthalate beads for domestic wastewater treatment: Modelling approach and fouling control, Bioresour. Technol. 258 (2018) 263-269.

[47] J. Park, K. Jeong, S. Baek, S. Park, M. Ligaray, T.H. Chong, K.H. Cho, Modeling of NF/RO membrane fouling and flux decline using real-time observations, J. Memb. Sci. 576 (2019) 66-77.

[48] W.J. Cosgrove, D.P. Loucks, Water management: Current and future challenges and research directions, Water Resour. Res. 51 (2015) 4823-4839.

[49] D.E. McNabb, Global Pathways to Water Sustainability, Springer, 2019.

[50] M. Selebatso, G. Maude, R.W.S. Fynn, Assessment of quality of water provided for wildlife in the Central Kalahari Game Reserve, Botswana, Phys. Chem. Earth. 105 (2018) 191-195.

[51] J. Ma, X. Guo, Y. Ying, D. Liu, C. Zhong, Composite ultrafiltration membrane tailored by MOF@ GO with highly improved water purification performance, Chem. Eng. J. 313 (2017) 890-898.

[52] P. Senthil Kumar, A. Saravanan, Sustainable wastewater treatments in textile sector, in: Sustain. Fibres Text., Elsevier Inc., 2017: pp. 323-346.

[53] M. Dilaver, S.M. Hocaoğlu, G. Soydemir, M. Dursun, B. Keskinler, İ. Koyuncu, M. Ağtaş, Hot wastewater recovery by using ceramic membrane ultrafiltration and its reusability in textile industry, J. Clean. Prod. 171 (2018) 220-233.

[54] L. Gebrati, M. El Achaby, H. Chatoui, M. Laqbaqbi, J. El Kharraz, F. Aziz, Inhibiting effect of textile wastewater on the activity of sludge from the biological treatment process of the activated sludge plant, Saudi J. Biol. Sci. 26 (2019) 1753-1757.

[55] S. Zinadini, V. Vatanpour, A.A. Zinatizadeh, M. Rahimi, Z. Rahimi, M. Kian, Preparation and characterization of antifouling graphene oxide/polyethersulfone ultrafiltration membrane: application in MBR for dairy wastewater treatment, J. Water Process Eng. 7 (2015) 280-294.

[56] Y. Yoon, J. Ryu, J. Oh, B.G. Choi, S.A. Snyder, Occurrence of endocrine disrupting compounds, pharmaceuticals, and personal care products in the Han River (Seoul, South Korea), Sci. Total Environ. 408 (2010) 636-643.

[57] S.O. Ganiyu, E.D. Van Hullebusch, M. Cretin, G. Esposito, M.A. Oturan, Coupling of membrane filtration and advanced oxidation processes for removal of pharmaceutical residues: a critical review, Sep. Purif. Technol. 156 (2015) 891-914. 
[58] W. Yu, Y. Yang, N. Graham, Evaluation of ferrate as a coagulant aid/oxidant pretreatment for mitigating submerged ultrafiltration membrane fouling in drinking water treatment, Chem. Eng. J. 298 (2016) 234-242.

[59] Y. Pan, Z. Yu, H. Shi, Q. Chen, G. Zeng, H. Di, X. Ren, Y. He, A novel antifouling and antibacterial surface-functionalized PVDF ultrafiltration membrane via binding Ag/SiO 2 nanocomposites, J. Chem. Technol. Biotechnol. 92 (2017) 562-572.

[60] J. Zhang, Z. Xu, M. Shan, B. Zhou, Y. Li, B. Li, J. Niu, X. Qian, Synergetic effects of oxidized carbon nanotubes and graphene oxide on fouling control and anti-fouling mechanism of polyvinylidene fluoride ultrafiltration membranes, J. Memb. Sci. 448 (2013) 81-92.

[61] S. Qiu, L. Wu, X. Pan, L. Zhang, H. Chen, C. Gao, Preparation and properties of functionalized carbon nanotube/PSF blend ultrafiltration membranes, J. Memb. Sci. 342 (2009) 165-172.

[62] S.J. Oh, N. Kim, Y.T. Lee, Preparation and characterization of PVDF/TiO2 organicinorganic composite membranes for fouling resistance improvement, J. Memb. Sci. 345 (2009) 13-20.

[63] Z. Xu, J. Zhang, M. Shan, Y. Li, B. Li, J. Niu, B. Zhou, X. Qian, Organosilanefunctionalized graphene oxide for enhanced antifouling and mechanical properties of polyvinylidene fluoride ultrafiltration membranes, J. Memb. Sci. 458 (2014) 1-13.

[64] J. Zhang, Z. Xu, W. Mai, C. Min, B. Zhou, M. Shan, Y. Li, C. Yang, Z. Wang, X. Qian, Improved hydrophilicity, permeability, antifouling and mechanical performance of PVDF composite ultrafiltration membranes tailored by oxidized low-dimensional carbon nanomaterials, J. Mater. Chem. A. 1 (2013) 3101-3111.

[65] Z. Wang, H. Yu, J. Xia, F. Zhang, F. Li, Y. Xia, Y. Li, Novel GO-blended PVDF ultrafiltration membranes, Desalination. 299 (2012) 50-54.

[66] E. Celik, H. Park, H. Choi, H. Choi, Carbon nanotube blended polyethersulfone membranes for fouling control in water treatment, Water Res. 45 (2011) 274-282.

[67] H. Susanto, M. Ulbricht, Characteristics, performance and stability of polyethersulfone ultrafiltration membranes prepared by phase separation method using different macromolecular additives, J. Memb. Sci. 327 (2009) 125-135.

[68] A. Razmjou, J. Mansouri, V. Chen, The effects of mechanical and chemical modification of TiO2 nanoparticles on the surface chemistry, structure and fouling performance of PES ultrafiltration membranes, J. Memb. Sci. 378 (2011) 73-84.

[69] K. Zodrow, L. Brunet, S. Mahendra, D. Li, A. Zhang, Q. Li, P.J.J. Alvarez, Polysulfone ultrafiltration membranes impregnated with silver nanoparticles show improved biofouling resistance and virus removal, Water Res. 43 (2009) 715-723.

[70] G. Teijon, L. Candela, K. Tamoh, A. Molina-Díaz, A.R. Fernández-Alba, Occurrence of emerging contaminants, priority substances (2008/105/CE) and heavy metals in treated wastewater and groundwater at Depurbaix facility (Barcelona, Spain), Sci. Total Environ. 408 (2010) 3584-3595. 
[71] A. Salahi, M. Abbasi, T. Mohammadi, Permeate flux decline during UF of oily wastewater: Experimental and modeling, Desalination. 251 (2010) 153-160.

779

780

781

782

783

784

785

786

787

788

789

790

791

792

793

794

795

796

797

798

799

800

801

802

803

804

805

806

807

808

809

810

811

812

813

814

815

816

[72] L. Yan, S. Hong, M.L. Li, Y.S. Li, Application of the Al2O3-PVDF nanocomposite tubular ultrafiltration (UF) membrane for oily wastewater treatment and its antifouling research, Sep. Purif. Technol. 66 (2009) 347-352.

[73] E. Yuliwati, A.F. Ismail, Effect of additives concentration on the surface properties and performance of PVDF ultrafiltration membranes for refinery produced wastewater treatment, Desalination. 273 (2011) 226-234.

[74] M.A. Barakat, E. Schmidt, Polymer-enhanced ultrafiltration process for heavy metals removal from industrial wastewater, Desalination. 256 (2010) 90-93.

[75] N. Maximous, G. Nakhla, W. Wan, K. Wong, Preparation, characterization and performance of Al2O3/PES membrane for wastewater filtration, J. Memb. Sci. 341 (2009) 67-75.

[76] K. Singh, S. Arora, Removal of synthetic textile dyes from wastewaters: A critical review on present treatment technologies, Crit. Rev. Environ. Sci. Technol. 41 (2011) 807-878.

[77] Q. Sui, J. Huang, S. Deng, G. Yu, Q. Fan, Occurrence and removal of pharmaceuticals, caffeine and DEET in wastewater treatment plants of Beijing, China, Water Res. 44 (2010) 417-426.

[78] J. Margot, C. Kienle, A. Magnet, M. Weil, L. Rossi, L.F. de Alencastro, C. Abegglen, D. Thonney, N. Chèvre, M. Schärer, D.A. Barry, Treatment of micropollutants in municipal wastewater: Ozone or powdered activated carbon?, Sci. Total Environ. 461-462 (2013) 480-498.

[79] E.R. Lumban Gaol, S. Nasir, H. Hermansyah, A. Mataram, Rubber Industry Wastewater Treatment Using Sand Filter, Bentonite and Hybrid Membrane (UF-RO), Sriwij. J. Environ. 4 (2019) 14-18.

[80] M.F. Tay, C. Liu, E.R. Cornelissen, B. Wu, T.H. Chong, The feasibility of nanofiltration membrane bioreactor (NF-MBR)+reverse osmosis (RO) process for water reclamation: Comparison with ultrafiltration membrane bioreactor (UF-MBR)+RO process, Water Res. 129 (2018) 180-189.

[81] M. Badruzzaman, N. Voutchkov, L. Weinrich, J.G. Jacangelo, Selection of pretreatment technologies for seawater reverse osmosis plants: A review, Desalination. 449 (2019) 7891.

[82] H. Chang, T. Li, B. Liu, C. Chen, Q. He, J.C. Crittenden, Smart ultrafiltration membrane fouling control as desalination pretreatment of shale gas fracturing wastewater: The effects of backwash water, Environ. Int. 130 (2019).

[83] R. Krüger, D. Vial, P. Buchta, R. Winkler, Use of innovative inge ${ }^{\circledR}$ Multibore ${ }^{\circledR}$ ultrafiltration membranes for the treatment of challenging seawater, Desalin. Water Treat. 57 (2016) 22902-22908.

[84] B.S. Lalia, V. Kochkodan, R. Hashaikeh, N. Hilal, A review on membrane fabrication: Structure, properties and performance relationship, Desalination. 326 (2013) 77-95. 
[85] D. Datta, S. Bhattacharjee, A. Nath, R. Das, C. Bhattacharjee, S. Datta, Separation of ovalbumin from chicken egg white using two-stage ultrafiltration technique., Sep. Purif. Technol. 66 (2009) 353-361.

[86] R. Navarro-Lisboa, C. Herrera, R.N. Zúñiga, J. Enrione, F. Guzmán, S. Matiacevich, C. Astudillo-Castro, Quinoa proteins (Chenopodium quinoa Willd.) fractionated by ultrafiltration using ceramic membranes: The role of $\mathrm{pH}$ on physicochemical and conformational properties, Food Bioprod. Process. 102 (2017) 20-30.

[87] M.Z.M. Nor, L. Ramchandran, M. Duke, T. Vasiljevic, Separation of bromelain from crude pineapple waste mixture by a two-stage ceramic ultrafiltration process, Food Bioprod. Process. 98 (2016) 142-150.

[88] L.T. Rodríguez Furlán, M.E. Campderrós, Effect of Mg2+ binding on transmission of bovine serum albumin (BSA) through ultrafiltration membranes, Sep. Purif. Technol. 150 (2015) $1-12$.

[89] T.E. Thomas, S. Al Aani, D.L. Oatley-Radcliffe, P.M. Williams, N. Hilal, Laser Doppler Electrophoresis and electro-osmotic flow mapping: A novel methodology for the determination of membrane surface zeta potential, J. Memb. Sci. 523 (2017) 524-532.

[90] B.D. McCloskey, H.B. Park, H. Ju, B.W. Rowe, D.J. Miller, B.J. Chun, K. Kin, B.D. Freeman, Influence of polydopamine deposition conditions on pure water flux and foulant adhesion resistance of reverse osmosis, ultrafiltration, and microfiltration membranes, Polymer (Guildf). 51 (2010) 3472-3485.

[91] B.D. McCloskey, H.B. Park, H. Ju, B.W. Rowe, D.J. Miller, B.D. Freeman, A bioinspired fouling-resistant surface modification for water purification membranes, J. Memb. Sci. 413-414 (2012) 82-90.

[92] C. Zhao, X. Xu, J. Chen, F. Yang, Effect of graphene oxide concentration on the morphologies and antifouling properties of PVDF ultrafiltration membranes, J. Environ. Chem. Eng. 1 (2013) 349-354. https://doi.org/10.1016/j.jece.2013.05.014.

[93] Y.C. Chiang, Y. Chang, A. Higuchi, W.Y. Chen, R.C. Ruaan, Sulfobetaine-grafted poly(vinylidene fluoride) ultrafiltration membranes exhibit excellent antifouling property, J. Memb. Sci. 339 (2009) 151-159.

[94] L.C. Clement, C. Avila-Casado, C. MacÉ, E. Soria, W.W. Bakker, S. Kersten, S.S. Chugh, Podocyte-secreted angiopoietin-like-4 mediates proteinuria in glucocorticoid-sensitive nephrotic syndrome, Nat. Med. 17 (2011) 117-122.

[95] F. Liu, M.R.M. Abed, K. Li, Preparation and characterization of poly(vinylidene fluoride) (PVDF) based ultrafiltration membranes using nano $\gamma$-Al2O3, J. Memb. Sci. 366 (2011) 97-103.

[96] S. Liang, Y. Kang, A. Tiraferri, E.P. Giannelis, X. Huang, M. Elimelech, Highly hydrophilic polyvinylidene fluoride (PVDF) ultrafiltration membranes via postfabrication grafting of surface-tailored silica nanoparticles, ACS Appl. Mater. Interfaces. 5 (2013) 6694-6703.

[97] B. Sarkar, S. DasGupta, S. De, Electric field enhanced fractionation of protein mixture using ultrafiltration, J. Memb. Sci. 341 (2009) 11-20. 
[98] Q. Chen, L. Zhao, L. Yao, Q. Chen, W. Ahmad, Y. Li, Z. Qin, The Application of Membrane Separation Technology in the Dairy Industry, in: Technol. Approaches Nov. Appl. Dairy Process., InTech, 2018.

[99] J. Paes, C.R. da Cunha, L.A. Viotto, Concentration of lycopene in the pulp of papaya (Carica papaya L.) by ultrafiltration on a pilot scale, Food Bioprod. Process. 96 (2015) 296-305.

[100] Y.H. Tan, P.S. Goh, A.F. Ismail, B.C. Ng, G.S. Lai, Decolourization of aerobically treated palm oil mill effluent (AT-POME) using polyvinylidene fluoride (PVDF) ultrafiltration membrane incorporated with coupled zinc-iron oxide nanoparticles, Chem. Eng. J. 308 (2017) 359-369.

[101] R.A. Tufa, G. Di Profio, E. Fontananova, A.H. Avci, E. Curcio, Forward Osmosis, Reverse Electrodialysis and Membrane Distillation, in: Curr. Trends Futur. Dev. Membr., Elsevier, 2019: pp. 365-385.

[102] J.P. Chen, S.L. Kim, Y.P. Ting, Optimization of membrane physical and chemical cleaning by a statistically designed approach, J. Memb. Sci. 219 (2003) 27-45.

[103] E. Alventosa-deLara, S. Barredo-Damas, M.I. Alcaina-Miranda, M.I. Iborra-Clar, Ultrafiltration technology with a ceramic membrane for reactive dye removal: Optimization of membrane performance, J. Hazard. Mater. 209-210 (2012) 492-500.

[104] S. Al Aani, C.J. Wright, N. Hilal, Investigation of UF membranes fouling and potentials as pre-treatment step in desalination and surface water applications, Desalination. 432 (2018) 115-127.

[105] C. Cojocaru, G. Zakrzewska-Trznadel, A. Jaworska, Removal of cobalt ions from aqueous solutions by polymer assisted ultrafiltration using experimental design approach. Part 1: optimization of complexation conditions, J. Hazard. Mater. 169 (2009) 599-609.

[106] I. Ahmed, K.S. Balkhair, M.H. Albeiruttye, A.A.J. Shaiban, Importance and Significance of UF/MF Membrane Systems in Desalination Water Treatment, in: Desalination, InTech, 2017.

[107] American Water Works Association, Microfiltration and Ultrafiltration Membranes for Drinking Water, First Edit, Denver, 2005.

[108] E. Gray, V., Cady, S., Curran, D., DeMuth, J., Eradiri, O., Hussain, M., ... \& Stippler, In Vitro Release Test Methods for Drug Formulations for Parenteral Applications, Dissolution Technol. 25 (2018) 8-13.

[109] Z. Li, H. Chen, Z. Zhuo, D. Huang, F. Luo, L. Chen, J. Wang, L. Guo, B. Qiu, Z. Lin, Electrochemiluminescence biosensor for hyaluronidase activity detection and inhibitor assay based on the electrostatic interaction between hyaluronic acid and Ru(bpy)32+, Sensors Actuators, B Chem. 275 (2018) 409-414.

[110] Z. Altintas, M. Gittens, J. Pocock, I.E. Tothill, Biosensors for waterborne viruses: Detection and removal, Biochimie. 115 (2015) 144-154.

[111] K. Beda-Maluga, H. Pisarek, I. Romanowska, J. Komorowski, J. Swietoslawski, K. Winczyk, Ultrafiltration -an alternative method to polyethylene glycol precipitation for macroprolactin detection, Arch. Med. Sci. 11 (2015) 1001-1007. 
[112] R.C.R. Beck, P.S. Chaves, A. Goyanes, B. Vukosavljevic, A. Buanz, M. Windbergs, A.W. Basit, S. Gaisford, 3D printed tablets loaded with polymeric nanocapsules: An innovative approach to produce customized drug delivery systems, Int. J. Pharm. 528 (2017) 268-279.

[113] M. Nasr, M. Dawoud, Sorbitol based powder precursor of cubosomes as an oral delivery system for improved bioavailability of poorly water soluble drugs, J. Drug Deliv. Sci. Technol. 35 (2016) 106-113.

[114] C.H. Liu, J. Qi, D.Z. Zhou, A.C. Ju, B.Y. Yu, Influence of ultrafiltration membrane on ophiopogonins and homoisoflavonoids in Ophiopogon japonicus as measured by ultra-fast liquid chromatography coupled with ion trap time-of-flight mass spectrometry, Chin. J. Nat. Med. 15 (2017) 121-141.

[115] T. Hembach, N., Alexander, J., Hiller, C., Wieland, A., \& Schwartz, Dissemination prevention of antibiotic resistant and facultative pathogenic bacteria by ultrafiltration and ozone treatment at an urban wastewater treatment plant, Sci. Rep. 9 (2019) 1-12.

[116] A. Fiaccadori, E., Regolisti, G., Maggiore, U., Parenti, E., Cremaschi, E., Detrenis, S., Caiazza, A., Cabassi, Ultrafiltration in heart failure, Am. Heart J. 161 (2011) 439-449.

[117] Q. Wu, Y. Xu, K. Yang, H. Cui, Y. Chen, M. Wang, Q. Zhu, W. Kang, C. Gao, Fabrication of membrane absorbers based on amphiphilic carbonaceous derivatives for selective endotoxin clearance, J. Mater. Chem. B. 5 (2017) 8219-8227.

[118] M. Hulko, V. Dietrich, I. Koch, A. Gekeler, M. Gebert, W. Beck, B. Krause, Pyrogen retention: Comparison of the novel medium cut-off (MCO) membrane with other dialyser membranes, Sci. Rep. 9 (2019).

[119] N. de Mas, D.C. Kientzler, D. Kleindienst, Endotoxin Removal from a Small-Molecule Aqueous Drug Substance Using Ultrafiltration: A Case Study, Org. Process Res. Dev. 19 (2015) 1293-1298.

[120] Q. Lan, Y. Wang, Carbonization of gradient phenolics filled in macroporous substrates for high-flux tight membranes: Toward ultrafiltration of polypeptides, J. Memb. Sci. 590 (2019).

[121] A. Zambrowicz, A. Zabłocka, Bobak, J. Macała, M. Janusz, A. Polanowski, T. Trziszka, A simple and rapid method of isolation of active polypeptide complex, yolkin, from chicken egg yolk, Food Chem. 230 (2017) 705-711.

[122] M.Z.M. Nor, L. Ramchandran, M. Duke, T. Vasiljevic, Separation of bromelain from crude pineapple waste mixture by a two-stage ceramic ultrafiltration process, Food Bioprod. Process. 98 (2016) 142-150.

[123] F.L. Gumes Lopes, J.B. Severo, R.R. de Souza, D.D. Ehrhardt, J.C. Curvelo Santana, E.B. Tambourgi, Concentration by membrane separation processes of a medicinal product obtained from pineapple pulp, Brazilian Arch. Biol. Technol. 52 (2009) 457-464.

[124] C. Emin, I. Katalia, E. Kurnia, M. Ulbricht, Development of polymer blend ultrafiltration membranes with combined size and charge selectivity, in: Adv. Membr. Technol. VII, 2016.

[125] D.L. Woerner, Membrane technology in textile operations, Koch membrane Systems, Wilmington, MA., 2003. 
[126] E. Alventosa-deLara, S. Barredo-Damas, M.I. Alcaina-Miranda, M.I. Iborra-Clar, Ultrafiltration technology with a ceramic membrane for reactive dye removal: Optimization of membrane performance, J. Hazard. Mater. 209-210 (2012) 492-500.

[127] X. Ma, P. Chen, M. Zhou, Z. Zhong, F. Zhang, W. Xing, Tight Ultrafiltration Ceramic Membrane for Separation of Dyes and Mixed Salts (both NaCl/Na 2 SO 4 ) in Textile Wastewater Treatment, Ind. Eng. Chem. Res. 56 (2017) 7070-7079.

[128] S. Varjani, R. Joshi, V.K. Srivastava, H.H. Ngo, W. Guo, Treatment of wastewater from petroleum industry: current practices and perspectives, Environ. Sci. Pollut. Res. (2019).

[129] R.S. Dobson, J.E. Burgess, Biological treatment of precious metal refinery wastewater: A review, Miner. Eng. 20 (2007) 519-532.

[130] B.H. Diya’Uddeen, W.M.A.W. Daud, A.R. Abdul Aziz, Treatment technologies for petroleum refinery effluents: A review, Process Saf. Environ. Prot. 89 (2011) 95-105.

[131] H. Chang, T. Li, B. Liu, R.D. Vidic, M. Elimelech, J.C. Crittenden, Potential and implemented membrane-based technologies for the treatment and reuse of flowback and produced water from shale gas and oil plays: A review, Desalination. 455 (2019) 34-57.

[132] A. Moslehyani, A.F. Ismail, M.H.D. Othman, T. Matsuura, Design and performance study of hybrid photocatalytic reactor-PVDF/MWCNT nanocomposite membrane system for treatment of petroleum refinery wastewater, Desalination. 363 (2015) 99-111.

[133] C. V. Vedavyasan, Pretreatment trends - an overview, Desalination. 203 (2007) 296-299.

[134] F. Knops, S. van Hoof, H. Futselaar, L. Broens, Economic evaluation of a new ultrafiltration membrane for pretreatment of seawater reverse osmosis, Desalination. 203 (2007) 300-306.

[135] M. Busch, R. Chu, S. Rosenberg, Novel Trends in Dual Membrane Systems for Seawater Desalination: Minimum Primary Pretreatment and Low Environmental Impact Treatment Schemes, IDA J. Desalin. Water Reuse. 2 (2010) 56-71.

[136] S. Jamaly, N.N. Darwish, I. Ahmed, S.W. Hasan, A short review on reverse osmosis pretreatment technologies, Desalination. 354 (2014) 30-38.

[137] N. Voutchkov, Considerations for selection of seawater filtration pretreatment system, Desalination. 261 (2010) 354-364. 